\title{
Wnt Signaling in Oral Cancer Initiating Cells
}

\section{Citation}

Menon, Reshma S. 2017. Wnt Signaling in Oral Cancer Initiating Cells. Doctoral dissertation, Harvard School of Dental Medicine.

\section{Permanent link}

http://nrs.harvard.edu/urn-3:HUL.InstRepos:42080142

\section{Terms of Use}

This article was downloaded from Harvard University's DASH repository, and is made available under the terms and conditions applicable to Other Posted Material, as set forth at http:// nrs.harvard.edu/urn-3:HUL.InstRepos:dash.current.terms-of-use\#LAA

\section{Share Your Story}

The Harvard community has made this article openly available.

Please share how this access benefits you. Submit a story.

Accessibility 


\title{
WNT SIGNALING IN ORAL CANCER INITIATING CELLS
}

\author{
A Thesis Presented by \\ Reshma S. Menon, BDS \\ To \\ The Faculty of Medicine \\ in partial fulfillment of the requirements \\ for the degree of \\ Doctor of Medical Sciences
}

\begin{abstract}
Research Mentor: Zhe Li, PhD
Assistant Professor

Department of Medicine, Division of Genetics, Brigham and Women's Hospital
\end{abstract}

Boston, Massachusetts

April 2017 


\section{TABLE OF CONTENTS}

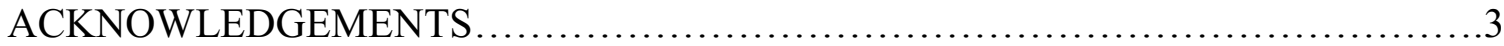

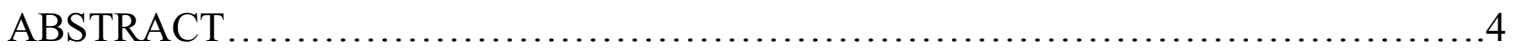

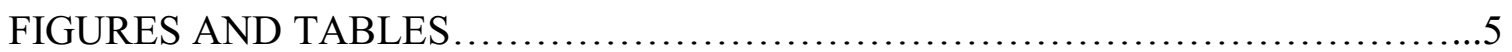

CHAPTER 1: INTRODUCTION AND REVIEW OF LITERATURE

i. Oral squamous cell carcinoma - the known and unknown $\ldots \ldots \ldots \ldots \ldots \ldots \ldots \ldots . . .8$

ii. Pathobiology of oral squamous cell carcinoma.............................. 10

iii. Heterogeneity in epithelial cancers and the cancer stem cell/cancer initiating cell

model............................................................... 13

iv. Stem cells in development, homeostasis and cancer........................13

v. Wnt signaling in oral squamous cell carcinoma............................ 17

vi. Cancer initiating cell model in oral squamous cell carcinoma....................18

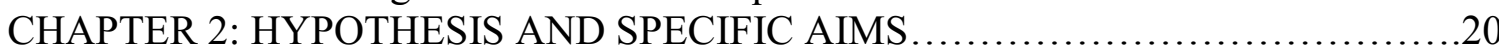

CHAPTER 3: SIGNIFICANCE ................................................ 22

CHAPTER 4: SPECIFIC AIM 1

i. Methods and rationale

a) 4-NQO mouse model of carcinogenesis for OSCC $\ldots \ldots \ldots \ldots \ldots \ldots \ldots \ldots .26$

b) Tissue processing and histological characterization......................27

c) Expression of Wnt signaling-related markers...........................28

ii. Results

a) 4-NQO-mouse model of carcinogenesis serves as a reliable surrogate to generate premalignant/malignant phenotypes noted in human OSCC........29

b) $\beta$-catenin is variably expressed in different stages of malignant progression in OSCC ............................................................

c) Wnt signaling is activated in epithelial dysplasia and OSCC and not in normal

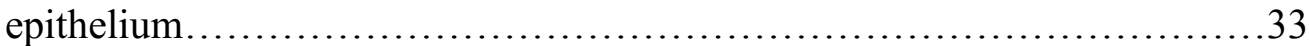

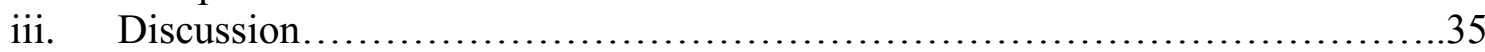

CHAPTER 5: SPECIFIC AIM 2

i. Methods and rationale

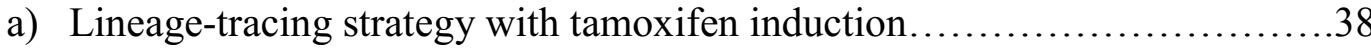

b) Transplantation assays in immunocompromised mouse models.............40

c) 3-D organoid culture platform ........................................ 41

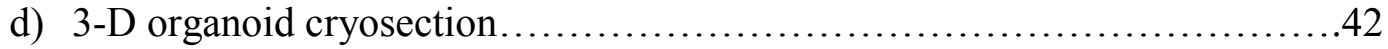

ii. Results

a) Axin2-positive cells are noted in OSCC and not in papillary epithelial hyperplasia......................................................42

b) Axin2 induction in organoids of primary OSCC cells reveals evidence of Wnt signaling............................................................ 45

c) Wnt-responsive CICs are capable of forming organoids..................46

iii. Discussion............................................................ 47

CHAPTER 6: CONCLUSIONS AND FUTURE PROJECTS ........................49

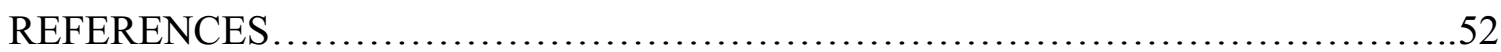




\section{ACKNOWLEDGMENTS}

I am incredibly grateful for the support and constant guidance that I have received from Dr. Zhe Li, the principal investigator of this project; Dr. Chia-Cheng Li who has been a great mentor and friend and all of the Li lab members, especially Drs. Hubert Pakula, Dongxi Xiang and Ying Xie.

I also want to thank the members of my thesis advisory committee; Dr. George F. Murphy, Dr. Peter Hammerman and Dr. Yingzi Yang for taking the time out of their busy schedules to help navigate this project successfully.

My program director, Dr. Sook-Bin Woo, who has been a great teacher through the years and who has taught me more in the past four years than I have learned in all my life.

Finally, I would like to thank our daughter, Medha, my husband, Umashankar and my family and friends for always being extremely loving and supportive. 


\section{ABSTRACT}

Oral cavity and pharynx cancer is the eighth most common malignancy amongst men in the United States, and more than five times this number are diagnosed on a global scale annually. Owing to the extremely heterogeneous nature of these tumors, the prognosis and survival rates are dismal and remain similar to what was reported over 20 years ago. Patients continue to be managed surgically with/without chemoradiation. More recently, targeted therapy was introduced with promising outcomes. To explain the heterogeneity of cancer, the concept of cancer initiating cells (CICs) has been extensively studied in epithelial cancers. These subpopulations of cancer cells can self-propagate and form heterogeneous clones that are capable of metastasis, recurrence and escaping conventional therapy. Targeting these specialized subpopulations will provide a relatively unexplored avenue to overcoming therapy resistance. As previously established, CICs and normal stem cells share common signaling pathways related to developmental and self-renewal programs. One such crucial pathway is the $\mathrm{Wnt} / \beta$-catenin signaling pathway, the constitutive activation of which is associated with many epithelial cancers, including oral squamous cell carcinoma. We thus hypothesize that the presence of Wnt signaling responsive CICs in oral premalignant lesions and squamous cell carcinoma contributes to the initiation, progression in these tumors and possibly resistance to standard therapy.

To address this hypothesis, we generated two aims; at the onset, we wanted to induce and bank premalignant lesions and oral squamous cell carcinoma (OSCC) and characterize these lesions at a histopathologic and molecular level. To generate OSCC tumors, we used a 4-NQO induced model in mice that were amenable to Cre/lox-based reporter lines for further characterization. After we successfully generated and banked primary tumors in this model, we characterized these tumors from a histological standpoint and immunolabeled these tumor cells for Wnt signaling-related markers. The progression of these tumors shared the phenotype of their human counterparts thus providing an effective platform to study the various tumor subpopulations. Other results revealed variable expression of $\beta$-catenin in premalignancy and OSCC. Interestingly, $\beta$-catenin nuclear positivity was noted in scattered cells at the invasive front of the malignant tumor islands. Further, rare populations of basal cells were positive for downstream markers of Wnt signaling such as $\beta$-catenin and LEF-1. Of note, this pattern of labeling was not noted in normal epithelium. Next, we planned to identify and study CICs in OSCC based on their activity for $\mathrm{Wnt} / \beta$-catenin signaling pathway. We resorted to utilizing lineagetracing experiments to identify and study CICs in OSCC. To visualize the fluorescent reporter, tamoxifen was administered, and lesions were traced for three days. Axin2 positive cells were noted in OSCC and not in papillary epithelial hyperplasia. To overcome the difficulties associated with in vivo tracing, a 3-D organoid platform was established to perform further lineage testing. Organoids from primary OSCC tumors were established and passaged. Further, upon Axin2 induction, evidence of Wnt signaling was noted in these organoids. These results suggest that Wnt activity is a key pathway upregulated in OSCC and further, it is plausible that these clones of cells will be susceptible to signaling pathway specific targeted therapeutics in the future for better outcomes. 


\section{FIGURES AND TABLES}

Figure 1. Canonical Wnt $\beta$-catenin signaling ................................ 15

Figure 2. 4-NQO Treatment strategy ........................................... 26

Figure 3. Gross images of normal tongue and lesions generated in the 4-NQO mouse model of OSCC............................................................... 30

Figure 4. Illustration for malignant progression in human OSCC .....................31

Figure 5. Histologic characterization of oral lesions in 4-NQO induced mouse model.

Figure 6. Immunohistochemical studies for $\beta$-catenin in oral lesions in 4-NQO induced

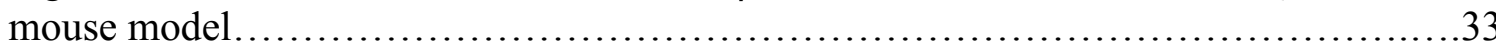

Figure 7. Immunofluorescence studies for $\beta$-catenin and LEF-1 in epithelial dysplasia and OSCC.

Figure 8. Immunofluorescence studies for $\beta$-catenin and LEF-1 in normal

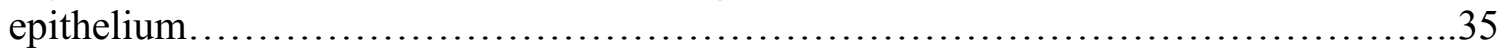

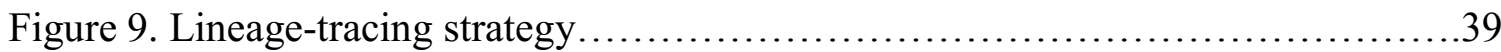

Figure 10. Lineage-tracing scheme in 4-NQO mouse model of OSCC...............40

Figure 11. Fluorescent reporter (Axin2) in papillary hyperplasia and OSCC...........43

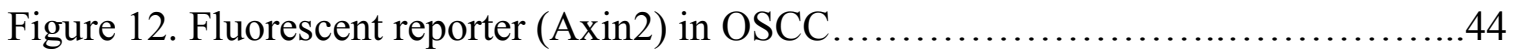

Figure 13. Fluorescent reporter (Axin2) in papillary hyperplasia...................45

Figure 14. Axin2 induction in OSCC organoids................................46

Figure 15. 3-D organoid cryosection........................................... 47 
CHAPTER 1: INTRODUCTION AND REVIEW OF LITERATURE 
The earliest descriptions of cancer (albeit unnamed at the time) date back to $3000 \mathrm{BC}$, in a chapter of a textbook on trauma surgery - Edwin Smith Papyrus, discovered in Egypt (American Cancer Society, www.cancer.org). Among the writings on the disease in the book, is a statement "There is no treatment." The evidence of this disease was seen in human mummies and fossilized tumors, some of which were noted to cause the destruction of the skull, as seen in head and neck cancers.

It was not until several thousands of years later that this disease term was coined by Greek physician and "Father of Medicine", Hippocrates, who used the terminologies carcinos and carcinoma. Celsus, a Roman physician later translated these terms to its Latin version, namely 'cancer'. The definition of cancer has remained unchanged from when it was first proposed over thousands of years ago, comparing the spreading and seeding of abnormal tumor cells to the unfurling finger-like projections, akin to that of a crab.

In 2012, the GLOBOCAN project of the International Agency for Research on Cancer (IARC) estimated the worldwide number of newly diagnosed cancer cases to be approximately 14.1 million, accounting for deaths in nearly $60 \%$ (1). In 2016 , an estimated 1.7 million cases were projected to cause deaths in over $35 \%$ in the United States, making it the second most common cause of death after cardiovascular disease (2). 


\section{Oral squamous cell carcinoma - the known and unknown}

Cancers arising in the oral cavity and pharynx comprise approximately $3 \%$ of all cancer cases $(48,330)$, accounting for over 9,570 deaths $(\sim 20 \%)$. Of these numbers, men have an astoundingly high incidence $(34,780)$, ranking it the eighth most common cancer in men in the USA (2). Globally, there is a wide geographic variation in the incidence of oral cancer, with over a quarter of a million newly diagnosed cases annually, making it the sixth most common cancer in the world. This variability is associated with significantly higher mortality rates in developing countries such as in Southeast Asia (48.5\% vs. $19.8 \%$ in developed countries) (3). The regional disparity may be attributed to the habit of smoking and chewing areca nut (4). More recently in developed countries, in addition to tobacco and alcohol, high-risk human papillomavirus infection (e.g., HPV-16 and HPV-18) has been identified as a significant risk factor for oral and oropharynx cancer $(3,5,6)$. Besides the commonly described environmental risk factors, some germline genetic alterations are also associated with a higher incidence of head and neck cancer.

Due to germline mutations of TP53, patients with Li-Fraumeni syndrome are predisposed to early-onset oral cancer (7). In addition, germline mutations of $C D K N 2 A$, a tumor suppressor gene, are associated with FAMMM (familial atypical multiple mole melanoma); these patients are predisposed to developing multiple melanomas, pancreatic cancer and head and neck cancer (8). A significantly higher ( $>500$ fold) risk for head and neck cancer is noted in patients with Fanconi Anemia, a syndrome characterized by mutations in DNA repair pathway genes (9). Patients with dyskeratosis congenita have a thousand fold risk of developing oral squamous cell carcinoma due to a defect in 
telomerase maintenance (10).

In the head and neck region, oral squamous cell carcinoma (OSCC) is the most common cancer type (over 90\%) and usually progresses rapidly (11). The well-established premalignant lesion of OSCC is a leukoplakia; after having excluded its clinical mimickers, these lesions histologically exhibit varying degrees of epithelial dysplasia. The World Health Organization (WHO) defines oral epithelial premalignancy as "morphologically altered tissue in which oral cancer is more likely to occur than in its apparently normal counterpart" (12). Globally, the estimated prevalence of leukoplakia is $2.6 \%$ (13); approximately $1-5 \%$ undergo malignant transformation annually (14-16). Nearly half of all leukoplakias exhibit epithelial dysplasia or invasive SCC when biopsied $(17-19)$.

Around $70 \%$ of patients with OSCC have regional/distant metastasis at the time of diagnosis. Additionally, OSCC tumors can double in size within three months; clinically this equates to a $\mathrm{T} 1$ tumor ( $2 \mathrm{cms}$ or less) progressing to a $\mathrm{T} 3$ (greater than $4 \mathrm{cms}$ ) in less than two years (20). This accelerated rate of progression corresponds to a dismal prognosis. The 5-year survival rate for OSCC varies between $83 \%$ for stage I cancers and $38 \%$ for stage IV cancers (2). Treatment strategies and prognosis for OSCC vary based on the stage at diagnosis. Patients with localized disease receive surgery and radiation; with regional/metastatic OSCC, chemotherapy with radiation is the mainstay of treatment. Other more recently introduced regimens and ongoing trials include targeted therapy, such as Cetuximab [anti-epidermal growth factor (EGFR)], Bevacizumab [anti- 
vascular endothelial growth factor (VEGF)], mechanistic-target of Rapamycin (m-TOR) inhibitors and kinase inhibitors (21). Monoclonal antibodies targeting receptors of immune escape pathways such as PD-1 (Nivolumab and Pembrolizumab) were recently approved for treatment in patients with platinum-refractory recurrent and metastatic head and neck squamous cell carcinoma (22).

Despite these advances, the challenge remains in the timely treatment of the primary tumor(s) and high recurrence rates (23). Local and regional recurrences occur in $30-40 \%$ of cases and distant metastases in $20-30 \%$ of the cases (24). In 1953, Slaughter and colleagues proposed the concept of 'field cancerization' to explain the high occurrence of synchronous and recurrent OSCC (25). Although several pathobiologic mechanisms have been proposed in oral premalignancy and OSCC since then, it is still unclear, what drives the process of field cancerization, recurrence and occult metastases.

\section{Pathobiology of oral squamous cell carcinoma}

The mutational landscape of head and neck squamous cell carcinoma has been studied extensively for nearly a decade. The mutational profile of HPV-positive and negative oropharyngeal carcinoma was noted to cluster into two distinct subgroups. TP53 mutations, $C C N D 1$ amplifications, and $C K N 2 A / B$ deletions were exclusively detected in all HPV-negative oropharyngeal cancers. On the other hand, PIK3CA mutations or amplifications and PTEN inactivation were seen in a majority of the HPV-positive tumors (26). For this project, we chose to study HPV-negative OSCC and the remainder of the discussion will highlight the pathobiological mechanisms of this entity. 
Haddad et. al published one of the seminal review papers on the molecular advances in head and neck cancer. Some of the genetic instabilities discussed include loss of heterozygosity of chromosomes $3 \mathrm{p}$ and $8 \mathrm{p}$, among others and dysregulation of oncogenes and tumor suppressor genes such as those encoding epidermal growth factor receptor (EGFR), p53, Rb, p65, cyclooxygenase 2 (COX-2), cyclin D1, p16 and phosphatase and tensin homolog (PTEN). Other genes, including those encoding E-cadherin (CDH1), vascular endothelial growth factor (VEGF), fibroblast growth factor (FGF), chemokine (C-X-C motif) receptor-stromal-cell-derived factor (CXCR4-SDF-1), platelet-derived growth factor (PDGF), transforming growth factor $\alpha$ and $\beta$ (TGF- $\alpha$ and TGF- $\beta$ ), interleukin-8, and matrix metalloproteinase (MMP) have been implicated in the early stages of tumor progression and metastasis (21). In 2011, two groups simultaneously performed whole exome sequencing on patient tumor samples and confirmed previously described mutations i.e. TP53, CDKN2A, PTEN, PIK3CA, and HRAS. Beyond this, newly discovered mutations of regulators of squamous differentiation such as $\mathrm{NOTCH} 1$ were identified and implicated in the carcinogenesis of these tumors $(27,28)$. More recently, loss of function alterations have been detected in Wnt pathway genes such as FATl and $A J U B A(29)$. In addition to encoding membranous protocadherins, FAT1 also binds $\beta$ catenin thus inhibiting Wnt activation; loss of function mutations of FAT1 is associated with increased risk for many types of human cancer (30). AJUBA is an LIM domain containing protein and is essential for E-cadherin-mediated adhesion (31); loss of function mutations have been described in around $5 \%$ of head and neck squamous cell carcinoma (32). 
More recently, clinical outcomes have been correlated to genomic profiling of these tumors revealing a higher association of $P I K 3 C A$ amplifications and $R A S$ mutations with worse prognosis (33).

The initiation and progression of OSCC has been linked to a trifecta of events; including the above-mentioned genetic mutations, as well as epigenetic and microRNA alterations. Epigenetic events are acquired and cause changes at the level of the phenotype by altering the structure of the chromatin, without affecting the genotype, seen as DNA hypermethylation and post-translational histone modifications (34). Promoter hypermethylation of tumor suppressor genes such as those encoding p16, MGMT and Ecadherin were commonly noted (up to 60\%) in oral leukoplakias and OSCC (35). Also, hypermethylation of $C D H 1$ and $D A P K$ has been noted in OSCC (36-38). Unfortunately there is little evidence currently to prove that epigenetic changes correlate clinically with prognosis and recurrence.

MicroRNAs (miRNAs) have also been implicated in the initiation and progression in OSCC. MiRNAs are short, single-stranded, non-coding RNAs that function by posttranscriptional repression of target gene expression (39). Some of the mechanisms leading to altered expression of miRNAs and thus initiation and progression of malignancy include transcriptional dysregulation, epigenetic modifications, chromosomal changes, single nucleotide polymorphisms (SNPs) or defects in the processing machinery $(40,41)$. Finally, around 50 altered miRNAs have been linked to the pathogenesis of head and neck SCC (42). 


\section{Heterogeneity in epithelial cancers and the cancer stem cell/cancer initiating cell model}

It has been shown that epithelial cancers possess heterogeneity and some subpopulations of cancer cells possess stem cell-like properties (43). This cancer cell heterogeneity may be explained by at least three models: 1 . Cancer cells acquire somatic mutations and thus are genetically different; 2 . Cancer cells are organized in a hierarchy owing to epigenetic differences, and a specialized subpopulation of cancer stem/initiating cells (CSCs/CICs) exist that are capable of not only self-renewal but also asymmetric division; 3. Stochastic events cause otherwise identical cancer cells to undergo clonal expansion (or not) by chance (44-46).

These simple yet elegant 'hierarchical' models do not take into consideration, the crosstalk between the tumor cells and their microenvironment. Given the possibility of the role of the tumor microenvironment in defining the phenotype of $\mathrm{CSC} / \mathrm{CICs}$, a more 'dynamic' model has evolved. A more nuanced understanding of the stem cell associated signaling pathways in this more fluid model of CSCs will provide for a promising future to establish and testing new therapeutic targets (47).

\section{Stem cells in development, homeostasis, and cancer}

Stem cells are defined as "cells that have the ability to perpetuate themselves through self-renewal and to generate mature cells of a particular tissue through differentiation" (48). The phenomenon of tissue renewal and recycling was described over 50 years ago (49). The evidence of these rare populations of cells was obtained from the hemato- 
lymphoid system where such cells were isolated, regenerated and used therapeutically in the setting of bone marrow transplantation (50).

In recent years, stem cell biology has provided tremendous insights into cancer biology, with the two sharing several common features. Some of these include mechanistic similarities of auto-regulation of stem cells and tumor cells, stem cell-like features of tumor cells and the presence of cancer stem/initiating cells (CSC/CIC) within tumor cell populations. Stem cells and CSC/CICs often share similar pathways that regulate selfrenewal and differentiation (48), such as Wnt/ $\beta$-catenin signaling pathway. Canonical Wnt signaling pathway participates in the control of gene expression, cell fate and cell adhesion and polarity, often orchestrated with other pathways (e.g., Hedgehog and Notch signaling pathways) (51).

In the canonical Wnt/ $/$-catenin pathway, secreted Wnt ligands bind to the surface receptor complex, which consists of Frizzled and low-density lipoprotein (LDL) receptorrelated protein (LRP) $(52,53)$. The intracellular protein Disheveled (Dsh/Dvl) then disrupts the destruction complex consisting of Axin, APC (adenomatous polyposis coli), and GSK3 (glycogen synthase kinase 3), releasing transcriptional coactivator $\beta$-catenin (encoded by $C t n n b 1$ ) for nuclear translocation and activation of transcription factors (Tcf/Lef; T-cell specific transcription factor/lymphoid enhancer-binding factor), leading to activation of Wnt target genes. In the absence of Wnt signaling, the destruction complex phosphorylates $\beta$-catenin and leads to ubiquitination of $\beta$-catenin by proteasomes (54) (Fig. 1). Of note, $\beta$-catenin also forms an integral part of the cadherin 
complex, which controls intercellular adhesion and cell migration.
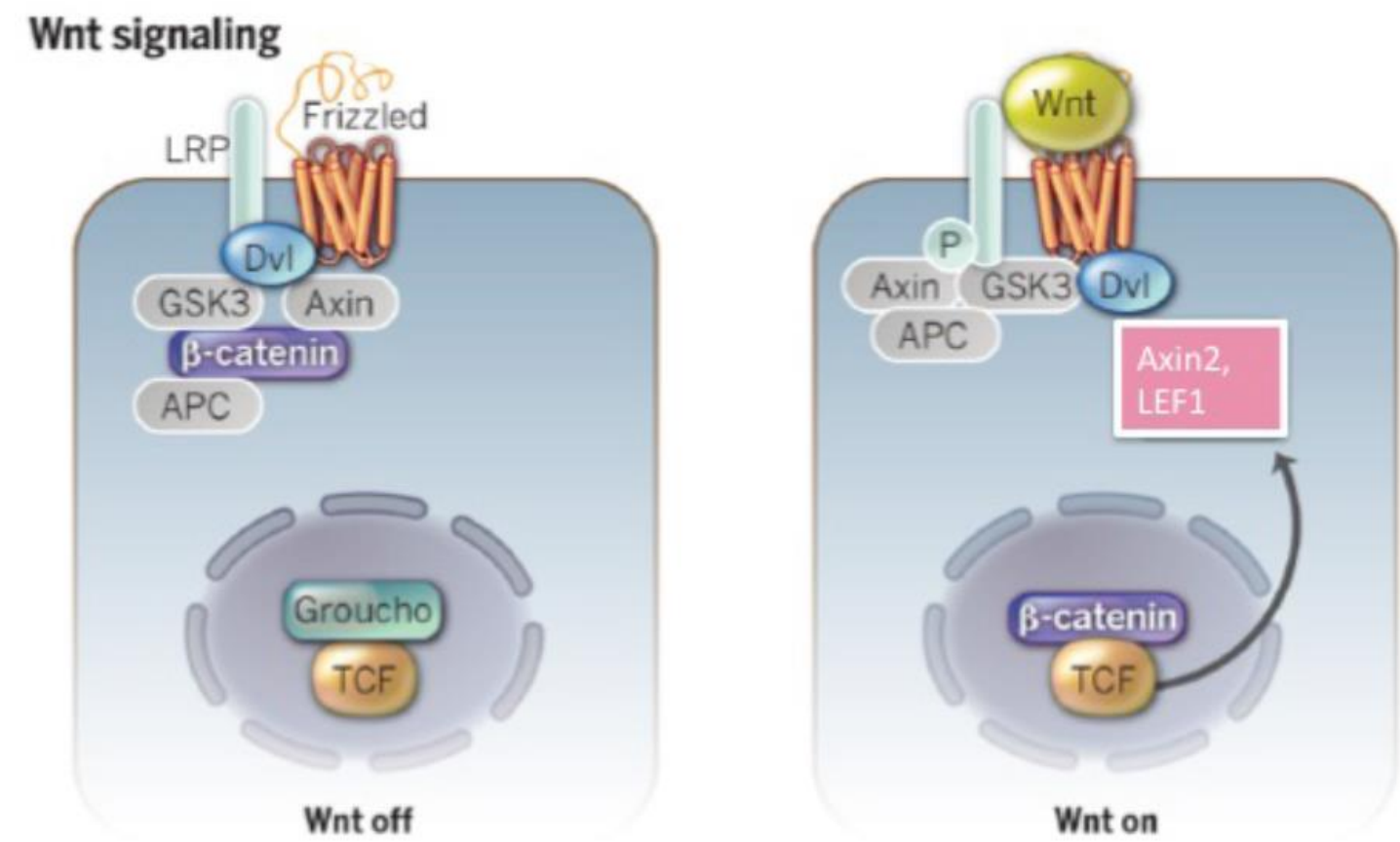

Wnt on

Figure 1. Canonical Wnt $\beta$-catenin signaling. (Left) In the absence of Wnt signaling, $\beta$ catenin is bound to a destruction complex composed of Axin, APC and GSK3 in the cytoplasm. Dvl is also required for the activation of the pathway. TCF is inactive within the nucleus and is bound to the repressor Groucho. (Right) When Wnt binds to its receptors, LRP is phosphorylated and associates with Axin. The destruction complex disintegrates leading to $\beta$-catenin getting stabilized in the nucleus. $\beta$-catenin then binds to TCF, leading to upregulation of target genes such as Ccnd1, Myc, Axin2 and Lgr5. Adapted from (55).

Wnt signaling is essential in normal homeostatic environments such as in the epidermis or intestines. Depending on the organization of the niche and tissue physiology, Wnt signaling may be responsible for delimiting the stem cell niche either by spatial restriction or by regulating differential expression of self-promoters and antagonists within the niche (55). In the epidermis, Wnt signaling plays a key role in "selforganizing" the stratified architecture by differentially controlling the expression of Wnt 
ligands in Axin2+ basal cells and long range Wnt antagonists such as Dkk3 that diffuse to suprabasal cell layers (56).

The constitutive activation of Wnt pathway has been associated with many epithelial cancers. The development of intestinal tumors is initiated by the hyper-activated, autorenewing crypt stem cells, following which accumulation of mutations confer malignancy and progression of cancer (57). In cell culture studies of normal human keratinocytes, higher levels of canonical Wnt signaling and $\beta$-catenin are associated with a greater proliferative potential (58). In models of chemically induced skin squamous cell carcinoma, nuclear $\beta$-catenin was found to be higher in CD34+ tumor cells and was established to be crucial in sustaining the CSC/CIC phenotype (59).

Several types of carcinoma cells acquire tumor-initiating stem cell-like capability after induction of the epithelial-mesenchymal transition (EMT) program and the residence of disseminating carcinoma cells in a stem-like state seems critical for tumor progression and metastasis (60). Additionally, acquisition of mesenchymal traits by EMT programming renders therapy resistance to $\mathrm{CSC} / \mathrm{CIC}$ populations (61).

Cancer stem cell (CSC) and cancer initiating cell (CIC) are often used interchangeably in the literature. For the sake of this project, we chose CIC as the preferred terminology for this model and henceforth refer to CSC/CIC as just CIC. 


\section{Wnt signaling in oral squamous cell carcinoma}

In the past, the role of $\beta$-catenin in the pathogenesis of OSCC has been linked primarily to its function in the cadherin complex and less significantly as the signaling molecule in the Wnt/ $\beta$-catenin pathway (62). Interestingly, patients with OSCC whose tumors demonstrated nuclear $\beta$-catenin expression in immunohistochemical studies were noted to have shorter overall survival than those lacking such a pattern (63). Furthermore, human OSCC samples with lymph node metastasis were analyzed for immunohistochemical studies of E-cadherin and $\beta$-catenin; the expression was found to be significantly reduced in these samples compared to those without lymph node metastasis (64). Decreased membranous staining of $\beta$-catenin at the tumor invasive front was closely associated with recurrence and death in human OSCC samples (65). Further, a 2-3-fold increase in $\beta$ catenin expression levels was noted in primary OSCC tumors (66).

In Side Population (SP) cells of OSCC, Wnt/ $\beta$-catenin signaling was abnormally activated; SP cells are a subset of Hoechst dye-low cells that are enriched for stem cells and found in many solid tumors and cancer cell lines. Furthermore, epigenetic alterations by DNA methylation and inactivation of WNT-inhibitors (e.g., SFRP, WIF-1 and DKK$3)$ were also noted $(67,68)$. The invasion and metastasis of OSCC cells in cell lines was noted to require the methylation of the E-cadherin gene $(\mathrm{CDH})$ and degradation of the membranous $\beta$-catenin (69). The peri and intranuclear localization of $\beta$-catenin in OSCC cell lines were associated with higher proliferation rates in growth assays (70). In transfected cells, the aberrant cytoplasmic accumulation of $\beta$-catenin was associated with enhanced invasion and migration of these cells via induction of Tcf/ Lef-1 mediated 
activity, upregulation of MMP-7, and epithelial-mesenchymal transition (EMT) (71).

Finally, in 4-NQO induced OSCC murine models, increased Wnt5a levels correlated with malignant transformation of tongue epithelium (72).

\section{Cancer initiating cell (CIC) model in oral squamous cell carcinoma}

As alluded to previously and similar to most epithelial tumors, OSCC exhibits marked heterogeneity. Significantly, these tumors tend to exhibit field cancerization and a high occurrence of synchronous and recurrent tumors (25). This clinical finding has led to the hypothesis that there exists a specialized clone of cells (cancer initiating cells; CICs) within OSCC that contributes to its progression, recurrence, and resistance to conventional therapy. The heterogeneity of these tumors may also be explained by the ability of these CICs to self-propagate and aberrantly give rise to heterogeneous subpopulations of cancer cells (73). Ultimately, developing therapeutic targets against CICs active for signaling pathways may be effective in eliminating these specialized clones of tumor cells and overcoming resistance to conventional therapy.

In OSCC, CICs may comprise less than $10 \%$ of the population of tumor cells, and these specialized subpopulations of OSCC cells can propagate and differentiate into therapy resistant heterogeneous clones (74). Many markers such as CD44, Bmi1, aldehyde dehydrogenase (ALDH) and CD133 in OSCC have been correlated with exhibiting stemlike features (73). 
Techniques to study and characterize CICs include flow cytometry, clonal analysis, immunohistochemical studies and serial transplantations (75). Although these assays describe the characteristics of these specialized populations of CICs, individually they provide little insight into the signaling mechanisms and behavior within the tumor microenvironment. Many recent studies utilizing lineage-tracing on epithelial tumors in murine models have demonstrated some success in tracing CICs based on known stem cell markers, such as K14 for basal cell carcinoma (45) and Lgr5 in intestinal crypt stem cells (46).

Based on the similarities in the principles of stem cell biology and cancer biology, it is plausible that CICs in OSCC are activated for such stem cell-related pathways and by identifying and characterizing these cells based on signaling pathways, we may be able to better understand the behavior of these tumors and develop novel therapeutic agents. Very recently, the presence of Bmi1+CICs was demonstrated to be responsible for the development of head and neck cancer and lymph node metastasis. It was also shown that targeting these Bmi1+ CICs along with targeting the tumor bulk effectively inhibited tumor growth and eliminated metastasis (76). 


\section{CHAPTER 2: HYPOTHESIS AND SPECIFIC AIMS}




\section{HYPOTHESIS}

Cancer-initiating cells active for the Wnt/ $\beta$-catenin signaling pathway contributes to tumor initiation and progression in oral squamous cell carcinoma.

\section{SPECIFIC AIMS}

AIM 1: To induce premalignant lesions and OSCC using a 4-NQO-induced mouse model and characterize these lesions at a histopathologic and molecular level.

AIM2: To demonstrate the stemness of Wnt-responsive OSCC cells. 
CHAPTER 3: SIGNIFICANCE 
Oral squamous cell carcinoma (OSCC) represents the sixth most common cancer in the world. Due to the heterogeneous nature of the tumors, there is a tendency for locoregional recurrences and metastasis in a third of the cases. As such, OSCC tumors demonstrate a sub-optimal response to chemotherapeutic agents and surgery remains the mainstay of therapy. To the end, to successfully manage these patients, novel targeted therapy is needed for the treatment and prevention of recurrence of OSCC. Like other epithelial tumors, OSCC tumors are extremely heterogeneous populations with a small percentage of cancer initiating cells (CICs) possessing stem-like traits. In addition to targeting the bulk of the tumor, therapies aimed at eliminating these rare CICs may help effectively prevent recurrence of these tumors. Many putative markers of CICs in OSCC have been described in cell lines, primary tumors and xenografts based on surface markers, Hoechst dye exclusion or activity for aldehyde dehydrogenase (ALDH) followed by transplantation assays. These experiments however only demonstrate the tumor forming potential of defined populations of OSCC cells, not necessarily how they behave in their native environment.

To better recapitulate the behavior of such specialized populations of tumor cells, we proposed to perform lineage-tracing experiments to label CICs in primary OSCC. Several recent studies in murine solid tumors (skin, intestinal tumors, and brain) utilizing lineage-tracing techniques have provided convincing evidence for the existence of specialized populations of CICs that are capable of giving rise to long-lived clones that lead to tumor progression, heterogeneity, and recurrence $(45,46,77)$. To effectively identify and characterize these populations, we wanted to study the role of $\mathrm{Wnt} / \beta$-catenin 
pathway signaling on the fate of CICs in OSCC. We aimed at characterizing OSCC premalignancy/tumors based on their expression of markers of Wnt/ $\beta$-catenin signaling.

Once we demonstrated this, we applied a lineage-tracing strategy, to be able to better study CICs and tumor cells in their intact environment and to link the features of stemness and signaling pathway activity. Finally, we will also develop a less expensive in vitro culture system to study the characteristics of CICs and to ultimately test therapeutic targets. 
CHAPTER 4: SPECIFIC AIM 1 


\section{SPECIFIC AIM 1}

To induce premalignant lesions and OSCC using a 4-NQO-induced mouse model and characterize these lesions at a histopathologic and molecular level.

\section{METHODS AND RATIONALE:}

\section{4-nitroquinoline 1-oxide (4-NQO) mouse model of carcinogenesis for OSCC}

Mice were treated with 4-nitroquinoline 1-oxide (4-NQO) (Sigma-Aldrich, Cat. no.

N8141), a DNA adduct forming agent that serves as a surrogate of tobacco exposure, in drinking water for 16 weeks.

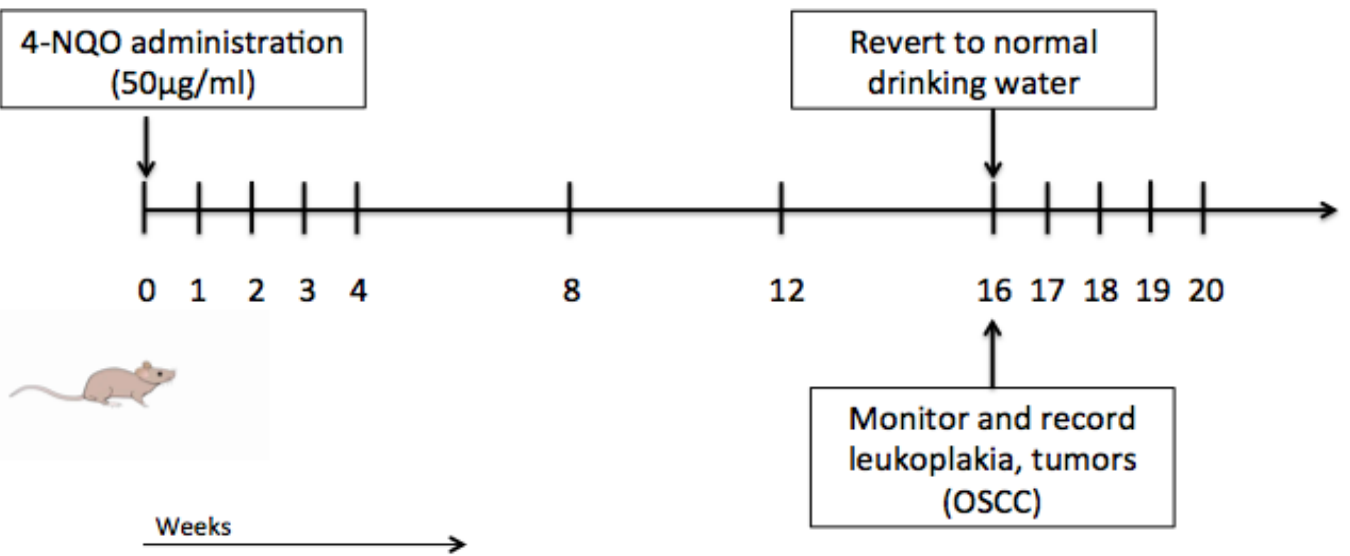

Figure 2. 4-NQO Treatment strategy. Mice were treated with 4-NQO in drinking water for 16 weeks.

The 4-NQO treated drinking water was prepared by dissolving 4-NQO powder in propylene glycol at $1 \mathrm{mg} / \mathrm{ml}$. This was then diluted in drinking water to a final concentration of $50 \mu \mathrm{g} / \mathrm{ml}$. The 4-NQO treated drinking water was changed weekly with a freshly prepared aliquot. After 16 weeks, the animal cages were reverted to regular 
drinking water (Fig. 2).

The 4-NQO dosing scheme $(50 \mu \mathrm{g} / \mathrm{mL} 4-\mathrm{NQO}$ in drinking water for 16 weeks) we used, helped limit non-neoplastic toxic effects of 4-NQO and lead to a very low incidence of esophageal neoplasia, but a $100 \%$ incidence of oral cancer (78).

All treated mice were subjected to a weekly, full oral cavity examination. Mucosal changes such as hyperkeratosis, papillomas, leukoplakia, erythroleukoplakia, ulceration and induration were recorded and monitored for changes in appearance. For mice that started to develop leukoplakia (white plaques) and oral cancer (indurated/ulcerated masses), we examined them 2-3 times/week for changes in tumor size/appearance and clinical signs (e.g., difficulty in feeding). Often, mice with large tumors had to be sacrificed, as they were frail or had difficulties with feeding.

Tumors from tongues were dissected and either stored in formalin at room temperature for processing and histopathologic analysis or banked in frozen medium, containing $10 \%$ DMSO with $90 \% \mathrm{FBS}$ and stored in $-80^{\circ} \mathrm{C}$. The archived tumors were stored such that it could be dissociated into single cells and used for transplantation assays or in vitro culture.

\section{Tissue processing and histological characterization}

The mice were euthanized in carbon dioxide chambers when large tumors were noted that interfered with feeding and caused generalized weakness. The tongues were then 
harvested, examined grossly for the presence of lesions and photographed. The tumors were dissected when well defined; if there was extensive involvement, the tongues were bisected. The specimens were then fixed in 10\% formaldehyde, embedded in paraffin and

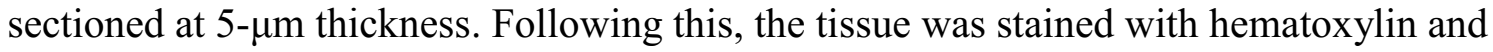
eosin (H\&E) and evaluated histopathologically for architectural and cytologic evidence of dysplasia and OSCC. Cytologic features such as pleomorphism, hyperchromatism, basal cell hyperplasia, dyskeratosis, abnormal mitotic figures and maturation disarray characterize oral epithelial dysplasia. In addition, architectural variations such as bulbous/tear-drop shaped rete ridges, dyscohesion, and keratin pearls are also indicative of dysplasia. OSCC exhibits similar cytologic features; architecturally, there is evidence of varying degrees of invasion (single cell vs. tumor islands) into underlying structures.

\section{Expression of Wnt signaling-related markers}

Axin2 is a direct target of the $\mathrm{Wnt} / \beta$-catenin signaling pathway. In this study we employed Axin2-CreERT; this system has been used for lineage-tracing studies to demonstrate the in vivo fate of $\mathrm{Wnt} / \beta$-catenin responsive stem cells (79). $\beta$-catenin is an important dual function protein that plays an essential role in the canonical Wnt/ $\beta$-catenin signaling pathway. Its nuclear translocation is essential to activate the downstream genes, such as LEF-1. Additionally, LEF-1 is a group of transcription factors that are responsible for mediating a nuclear response to Wnt signaling by its interaction with $\beta$ catenin. It was plausible that LEF-1 is overexpressed in basal cells and tumor islands in OSCC, indicating an increase in Wnt signaling activity in these cell populations. 
Immunohistochemical studies were performed on sections prepared at $5 \mu \mathrm{m}$ from paraffin-embedded tissue blocks. The embedded sections were de-waxed and then rehydrated, and antigen retrieval was carried out by boiling samples in sodium citrate buffer or Tris-hydrochloride buffers. After the slides were washed in TBS plus Triton, blocking agent ( $10 \%$ normal serum with $1 \% \mathrm{BSA})$ was applied at room temperature for an hour. This was drained and primary antibody diluted in blocking agent was added and incubated overnight at $4^{\circ} \mathrm{C}$. The following day, sections were washed with TBS plus Triton. Hydrogen peroxide substrate detection kit $\left(0.3 \% \mathrm{H}_{2} \mathrm{O}_{2}\right.$ in TBS for 15 min) was used and secondary antibody diluted in blocking agent was added and incubated for one hour at room temperature. This was then developed with chromogen, rinsed and counterstained and mounted using mounting medium and coverslip.

For immunofluorescence studies, sections were incubated with fluorescence-conjugated secondary antibodies in the dark. To visualize the nuclear DNA, DAPI was used along with the secondary antibodies.

\section{RESULTS:}

\section{4-NQO-mouse model of carcinogenesis serves as a reliable surrogate to generate premalignant/malignant phenotypes noted in human OSCC}

At 16 weeks or post-cessation of treatment with 4-NQO, most mice (>90\%) had developed leukoplakias or papillary lesions of the tongue. Around $20 \%$ of the cohort of 
mice had developed indurated and ulcerated tumors. When subsequently followed, a significantly higher percentage $(\sim 70 \%)$ of mice were noted to have indurated/ulcerated masses. These oral lesions affected feeding; causing weight loss and ultimately death in $50 \%$ of the cohort around 6-8 weeks post cessation of treatment; the rest were euthanized. All the animal studies were performed according to protocol no. 14-09-2764R*.
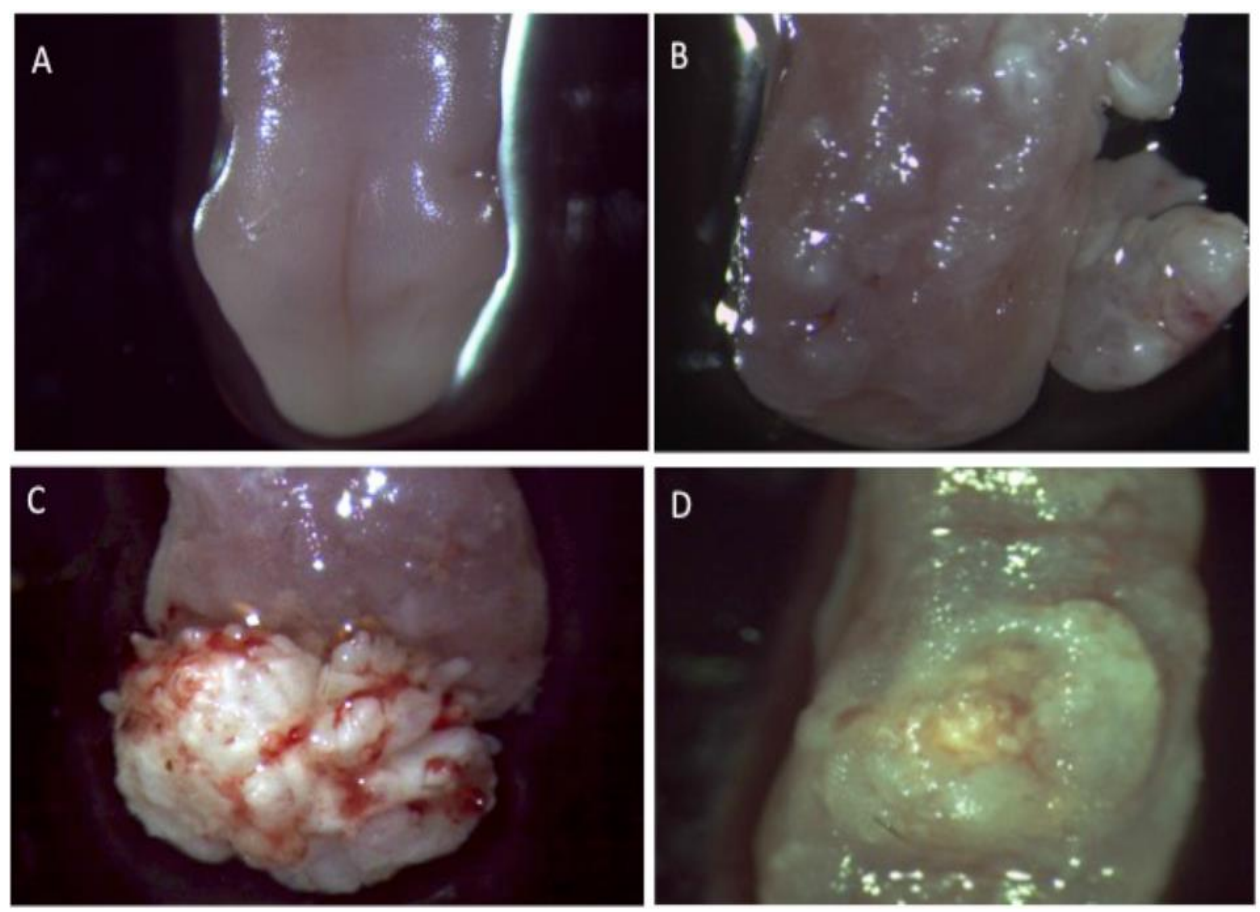

\section{Figure 3. Gross images of normal tongue and lesions generated in the 4-NQO mouse} model of OSCC. A. Normal tongue; B. Papillary hyperplasia on the left lateral tongue; C. Papillary hyperkeratosis of anterior dorsal tongue; D. Large, indurated and centrally ulcerated tumor (OSCC) of mid dorsal tongue.

Grossly, the tongue lesions were classified into four stages, normal, leukoplakia, papillary hyperplasia and OSCC (Fig. 3. A-D). The histologic characterization of the OSCC tumors generated was based on architectural and cytologic features as illustrated (Fig. 4). 


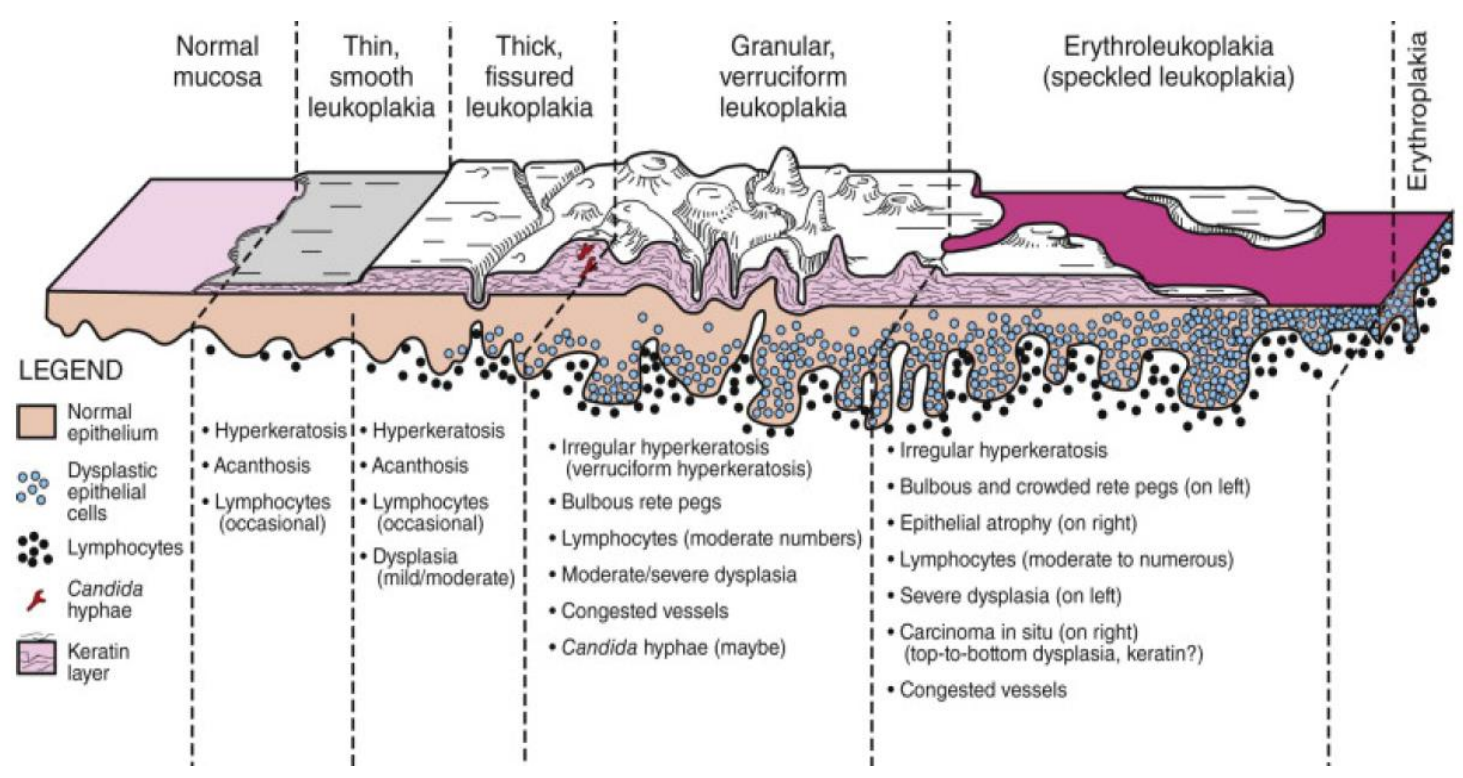

Figure 4. Illustration for malignant progression in human OSCC. (Adapted from Neville, Brad W., et al. Oral and maxillofacial pathology. Elsevier Health Sciences, 2015) (80).

Normal mucosa was characterized by a thin layer of parakeratin, epithelial thickness of 10-20 keratinocytes and tapered rete ridges without cytologic atypia (Fig. 5A). Papillary epithelial hyperplasia appeared as an exophytic well-differentiated papillary proliferation of epithelium with minimal cytologic atypia (Fig. 5B). Epithelial dysplasia and OSCC were characterized by pleomorphism, hyperchromatism, basal cell hyperplasia, dyskeratosis, abnormal mitotic figures and maturation disarray. Other architectural features such as bulbous/tear-drop shaped rete ridges, dyscohesion, and keratin pearls were also noted (Fig. 5C). Invasion into underlying lamina propria was noted in OSCC as either islands or single cells (Fig. 5D). 

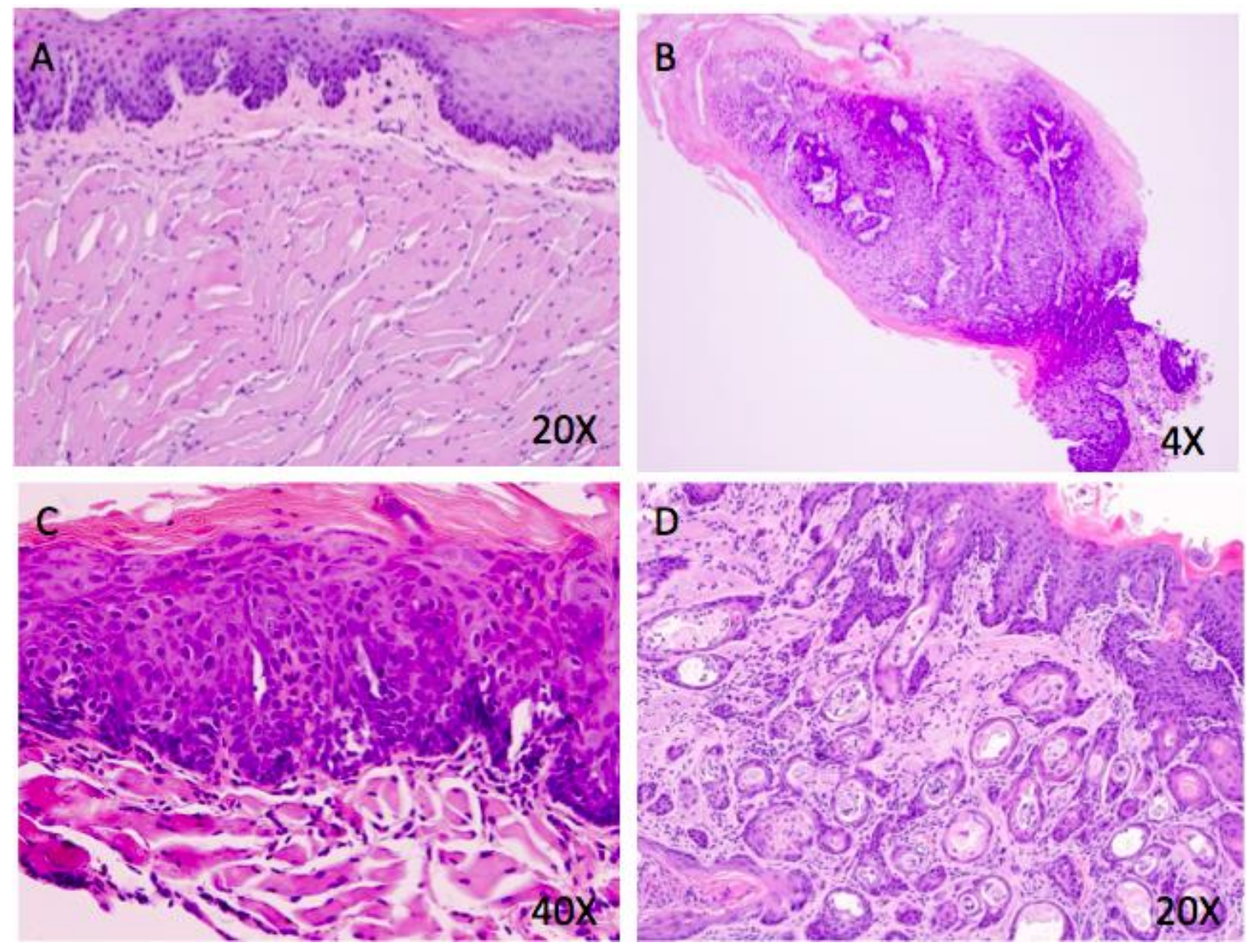

Figure 5. Histologic characterization of oral lesions in 4-NQO induced mouse model. A. Normal mucosa; B. Papillary epithelial hyperplasia; C. Epithelial dysplasia; D. OSCC.

The results of the histologic characterization of oral lesions in this chemically induced model of OSCC carcinogenesis revealed similar stages of malignant progression to that of human OSCC tumors. Thus it was established that the murine 4-NQO model was a reliable surrogate to study malignant progression in human OSCC.

$\beta$-catenin is variably expressed in different stages of malignant progression in OSCC Immunohistochemical studies for $\beta$-catenin were performed (Fig. 6. A-C). The studies for $\beta$-catenin in normal mucosa with mild hyperkeratosis showed membranous positivity in a majority of the epithelial keratinocytes (Fig. 6A). This membranous positivity was 
lost in the basal and suprabasal keratinocytes in epithelial dysplasia (Fig. 6B).
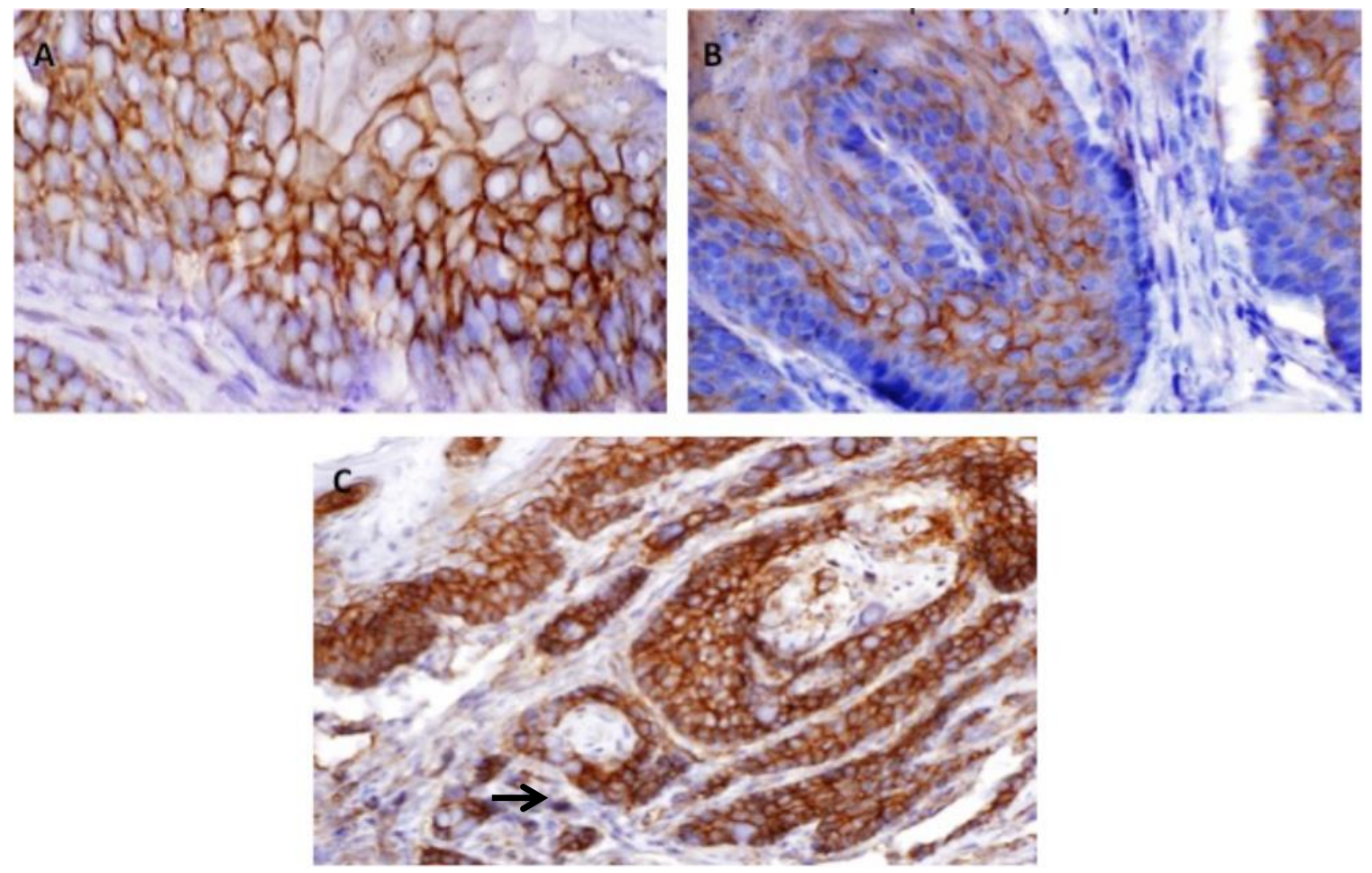

Figure 6. Immunohistochemical studies for $\beta$-catenin in oral lesions in 4-NQO induced mouse model. A. Mucosa with hyperkeratosis exhibiting membranous positivity; B. Epithelial dysplasia revealing loss of membranous staining in basal and suprabasal cells; C. OSCC with membranous and nuclear staining (black arrow - focal stromal cell nuclear positivity).

Interestingly in OSCC tumor cells, variable membranous and nuclear positivity for $\beta$ catenin was noted (Fig. 6C). In addition, a few cells at the invasive front exhibited intense nuclear positivity (black arrow), indicating increased Wnt signaling activity.

\section{Wnt signaling is activated in epithelial dysplasia and OSCC and not in normal}

\section{epithelium}

Immunofluorescence studies with markers of Wnt signaling were performed. The results 
of $\beta$-catenin and LEF-1 immunofluorescence studies in epithelial dysplasia (Fig. 7. A-B) revealed the presence of positive basal cells some of which co-expressed both markers. A similar result was noted in OSCC (Fig. 7. C-D), thus indicating that Wnt signaling activity was activated in some basal keratinocytes in both epithelial dysplasia and OSCC.
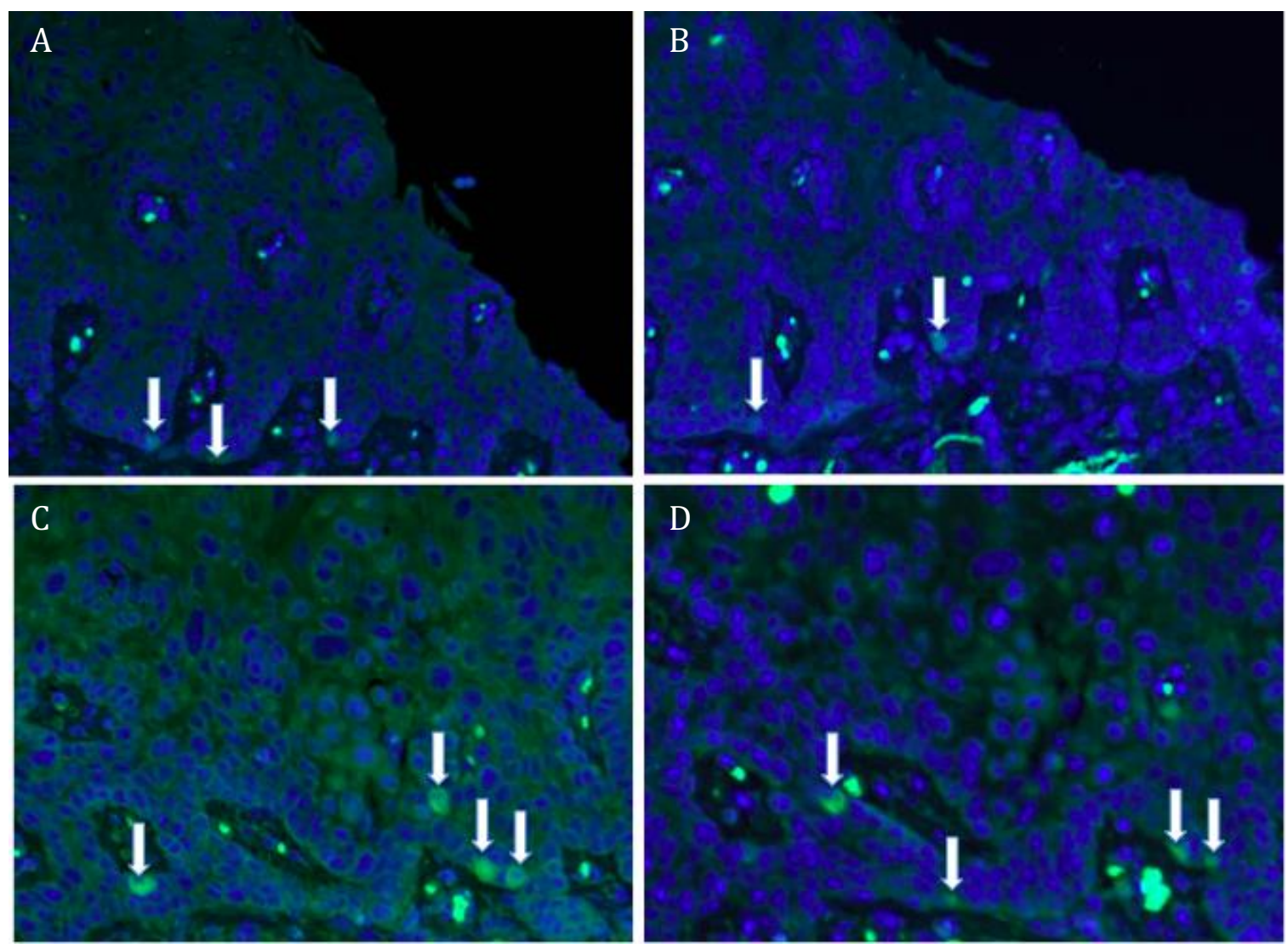

\section{Figure 7. Immunofluorescence studies for $\beta$-catenin and LEF-1 in epithelial} dysplasia and OSCC. (A and C) $\beta$-catenin and (B and D) LEF-1 immunofluorescence studies in epithelial dysplasia (A and B) and OSCC (C and D) reveal the presence of scattered immunofluorescence positive (green) cells in the basal and suprabasal cells (white arrows).

Interestingly, immunofluorescence studies for $\beta$-catenin and LEF-1 (Fig. 8. A-B) in normal epithelium failed to reveal any positive expression, thus permitting us to conclude 
that Wnt activity is not present or may be very rarely detected in normal epithelium.
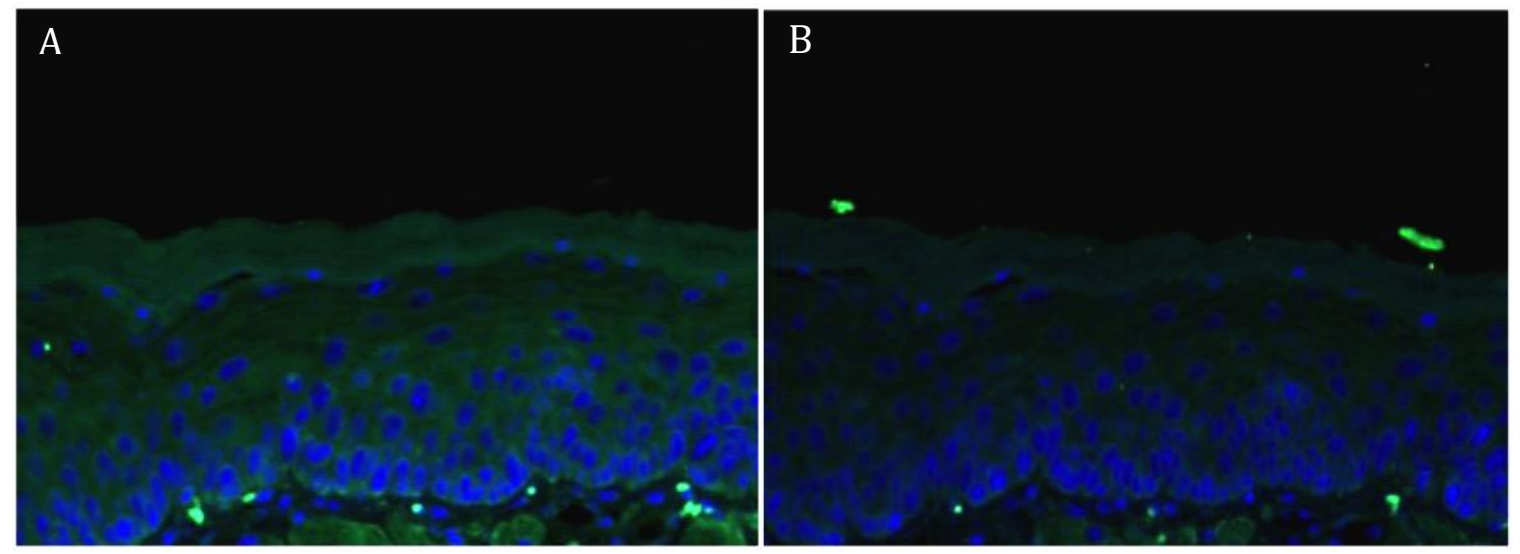

\section{Figure 8. Immunofluorescence studies for $\beta$-catenin and LEF-1 in normal} epithelium. A. $\beta$-catenin and B. LEF-1.

\section{DISCUSSION:}

In this aim, we sought to induce premalignant lesions and OSCC using a chemically induced model of carcinogenesis in mice using 4-NQO. We aimed to characterize the stages of malignant progression in this model and to compare our results to the wellestablished stages in human premalignancy and OSCC. The results of these experiments revealed that around 4-6 weeks after cessation of 4-NQO treatment, nearly $90 \%$ of the cohort of mice developed leukoplakias and tumors. The dosing scheme employed in this model helped minimize the occurrence of complications and death due to upper gastrointestinal tract tumors before the appearance of oral mucosal lesions. The various histologic stages of tumor progression included papillary hyperplasia, epithelial dysplasia, and invasive OSCC. Hence we were able to establish a 4-NQO-mouse model of carcinogenesis that serves as a reliable surrogate of malignant progression in human 
OSCC. We chose this model to generate an extensive archive of primary tumors that could be frozen and utilized in future experiments.

After the 4-NQO mouse model of carcinogenesis for OSCC was established, we generated the tumor bank and aimed at further characterizing the lesions and tumors at a molecular level for $\mathrm{Wnt} / \beta$-catenin signaling activity. Immunohistochemical and immunofluorescence studies were performed with reliable markers of the $\mathrm{Wnt} / \beta$-catenin pathway. The results of the immunohistochemical studies for $\beta$-catenin revealed variable expression in different stages of malignant progression. Specifically, in epithelial dysplasia, loss of membranous $\beta$-catenin staining was noted in the basal and suprabasal cells. Interestingly, in OSCC, membranous and nuclear staining of $\beta$-catenin was regained with intensely positive expression at the invasive front. This pattern of variable staining of $\beta$-catenin in the different stages of progression in OSCC may be indicative of an innate regulatory mechanism of Wnt signaling acquired by cancer initiating cells in the process of oncogenesis.

We also performed immunofluorescence studies for markers of Wnt signaling with $\beta$ catenin and LEF-1. These experiments revealed co-expression of both markers in 5-10\% of basal cells in epithelial dysplasia and OSCC indicating further evidence of Wnt signaling activity. Interestingly, immunofluorescence studies with $\beta$-catenin and LEF-1 in normal epithelium did not reveal any positivity. The results of these studies were extremely promising to preliminarily establish the presence of increased Wnt signaling activity in premalignancy and OSCC. 
CHAPTER 5: SPECIFIC AIM 2 


\section{SPECIFIC AIM 2}

To demonstrate the stemness of Wnt-responsive OSCC cells.

\section{METHODS AND RATIONALE:}

\section{Lineage-tracing strategy with tamoxifen induction}

In an attempt to study and model the cellular heterogeneity in cancer, several labeling strategies have been introduced over the past century. Lineage-tracing enables a single cell to be marked in a way that the cell's progeny retain the labeling thus generating distinct clones (81). Some of the techniques include direct observation, labeling cells with dyes and radioactive tracers, transfection or viral transduction for genetic marking, cell/tissue transplantation and genetic mosaics. We chose to use a more recently introduced approach of cell marking by genetic recombination specifically using the $\mathrm{Cre}$ loxP system.

To develop this system, two mice lines are crossed; in the first, Cre recombinase enzyme is expressed under the control of a tissue/cell-specific promoter and in the second mouse line a reporter is flanked by a floxed STOP (loxP-STOP-loxP) sequence. In animals that express both constructs, Cre activates the reporter in promoter-active cells by removing the STOP sequence (Fig. 9A). To selectively activate Cre in adult mice and to achieve temporal and spatial control, we utilized an inducible model of recombination (Fig. 9B). Cre recombinase is expressed as a fusion protein with the human estrogen receptor (ER). In its inactive form, without the presence of ligands like tamoxifen, the Cre recombinase- 
ER fusion protein remains in the cytoplasm. Upon introduction of ligands, activated CreER translocates to the nucleus, and Cre can then recombine the loxP sites (82).

For the sake of visualization, several fluorescent reporters are available. Some of the fluorophores utilized in mouse models include enhanced green fluorescent protein (EGFP), enhanced yellow fluorescent protein (EYFP), enhanced cyan fluorescent protein (ECFP) and tdTomato (83).

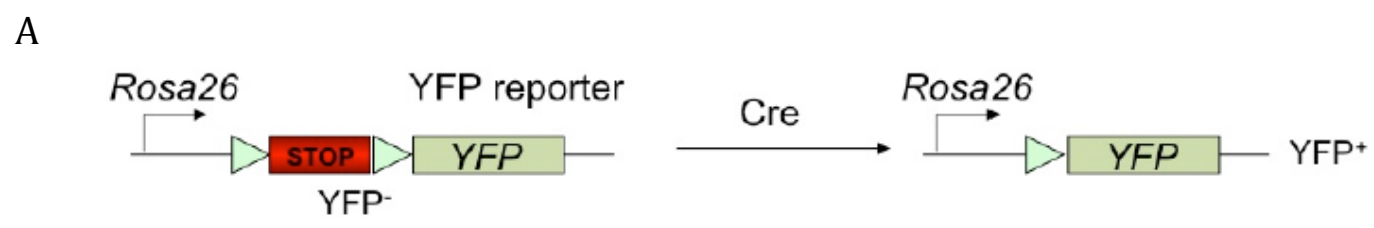

B

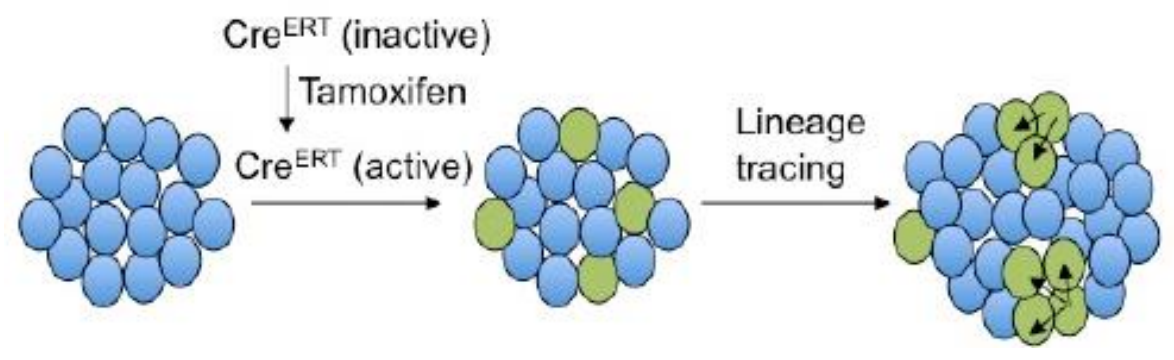

Figure 9. Lineage-tracing strategy. A. Rosa26-Stop-YFP reporter B. Tamoxifeninduced activation of CreERT causes labeling of tumor cells (blue) by YFP (green cells); YFP-labeled cells progress to form $\mathrm{YFP}^{+}$clones (arrows indicating generation of YFPmarked daughter cells from $\mathrm{YFP}^{+}$parental cells).

Our lab group studies epithelial cancer models extensively, and for the purpose of lineage-tracing studies, we chose to work with Cre/lox-based reporter lines to further characterize CICs in OSCC based on clonal analysis. The mouse strains that we selected 
were based on extensive literature review of the different signaling pathways associated with epithelial cancers. We chose to focus on Wnt/ $\beta$-catenin signaling pathway, and for this Axin2-CreERT reporter lines were employed (79). In addition, we utilized intraperitoneal tamoxifen injection to induce fluorescent labeling and visualize reporter positive cells (YFP or tdTomato) in the Axin2-CreERT-based system (Fig. 10).

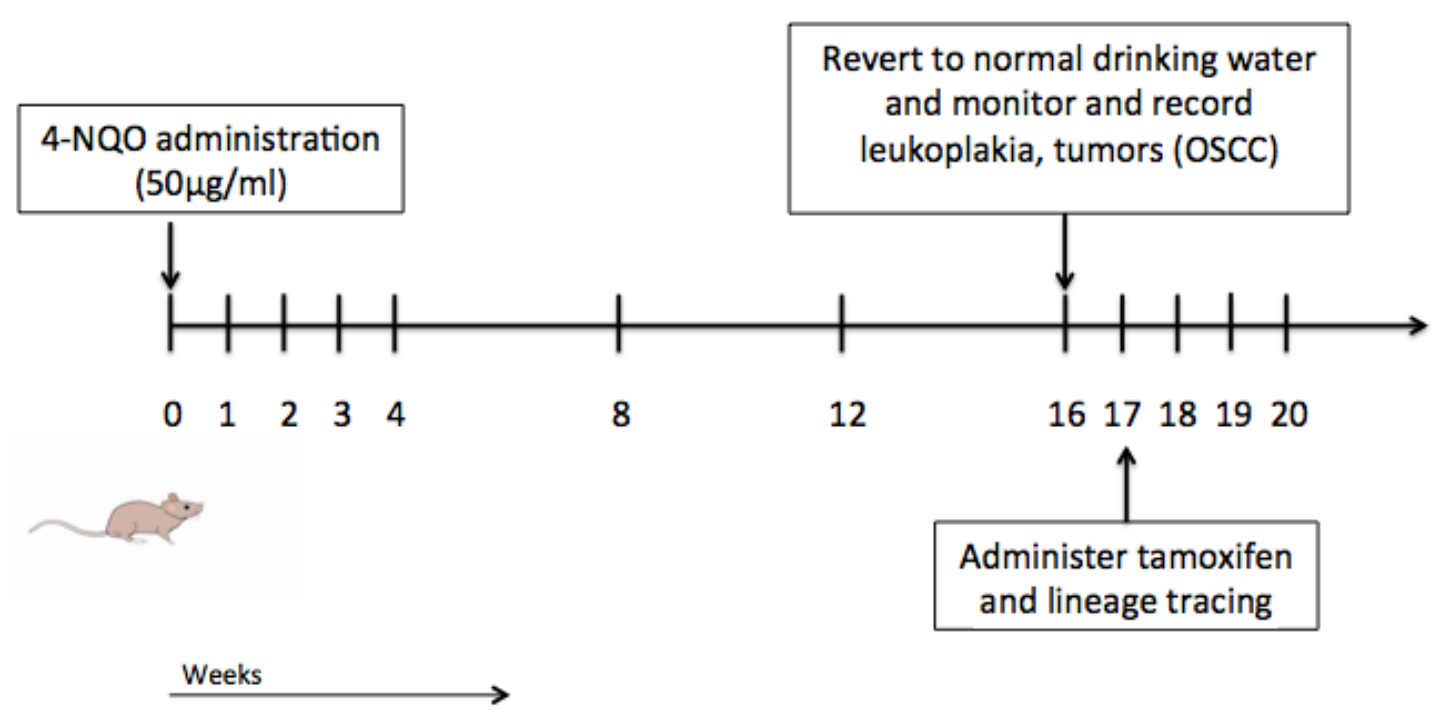

Figure 10. Lineage-tracing scheme in 4-NQO-mouse model of OSCC. Intraperitoneal injection of tamoxifen was administered after completion of 4-NQO treatment.

We expected to see evidence of heightened Wnt signaling activity and increased labeling of Axin2+ cells in the dysplastic/malignant epithelium that may eventually generate labeled clones.

\section{Transplantation assays in immunocompromised mouse models}

As alluded to earlier, one of the features that define CICs is its ability to regrow tumors when transplanted. We wanted to establish the potential of CICs from primary OSCC 
tumors to develop tumors when transplanted into immunodeficient mice. For this, either fresh tumor samples or cells from the frozen tumor bank were suspended in Matrigel and injected into immunodeficient mice. We attempted the transplantation assays in Rag2 knockout mice (a generous gift from Dr. Stuart Orkin's lab), athymic nude mice and NOD-SCID mice. The suspended tumor cells were injected either subcutaneously under the skin of the back or intraorally (either directly into the tongue or through an extraoral approach using a Hamilton microsyringe). The mice were monitored for 8-10 weeks, and no signs of tumor formation were noted. We repeated the transplantation assays with 3-D organoids from primary OSCC, and these failed to engraft in the immunodeficient mice models described above. We concluded that either the cell numbers that were transplanted were very small or further techniques of isolating pure populations of CICs based on stem cell markers had to be developed.

\section{3-D organoid culture platform}

A three-dimensional (3D) in vitro platform was set up to study lineage-tracing, clonal analysis and activity for Wnt signaling in primary OSCC tumor cells. For this, primary OSCC tumors that were obtained from mice were dissociated into single cells and were cultured in Matrigel (Corning), in the presence of cytokines. Basal culture medium comprised of Advanced DMEM/F12 (Gibco) supplemented with 2 mM GlutaMax (Life Tech), $10 \mathrm{mM}$ HEPES (Life Tech), and $100 \mathrm{U} / \mathrm{mL}$ penicillin/100 mg/mL streptomycin. The complete culture medium comprised of the basal culture medium with N2 supplement, B27 supplement (Life Tech), and $1 \mathrm{mM} N$-acetylcysteine (Sigma), $1 \mathrm{mg} / \mathrm{mL}$ Human R-Spondin-1 (Peprotech), 50 ng/mL human epidermal growth factor (Peprotech) 
and $100 \mathrm{ng} / \mathrm{mL}$ recombinant human Noggin (Peprotech). The culture medium was changed every other day, and the organoids were examined for changes in growth pattern or cell lysis. The clones were subsequently expanded and passaged. In some wells, 4hydroxytamoxifen was added to induce the CreER activity; the medium was replaced with fresh medium after two days.

\section{3-D organoid cryosection}

Finally, to study the architecture and labeling profile of the 3-D organoids cultures, cryosections were prepared from organoids two weeks after induction with tamoxifen. The organoids were fixed and frozen in OCT compound before they were cut at $8-\mu \mathrm{m}$ thickness. Subsequently, immunofluorescence studies for DAPI and YFP were performed using the previously described immunofluorescence protocol.

\section{RESULTS:}

\section{Axin2-positive cells are noted in OSCC and not in papillary epithelial hyperplasia}

Lineage-tracing experiments were performed at different stages of malignant progression in the Axin2-CreER-YFP/tdTomato mice. This was achieved with intraperitoneal injections of tamoxifen upon visualization of intraoral tumors. The administration of tamoxifen in these strains of mice would lead to Cre-mediated recombination and expression of fluorescent protein (YFP/tdTomato) in Axin2 positive cells (and their daughter cells). When tumors/lesions were visualized, the mice were euthanized and the tongue samples were collected three days after the injection. 

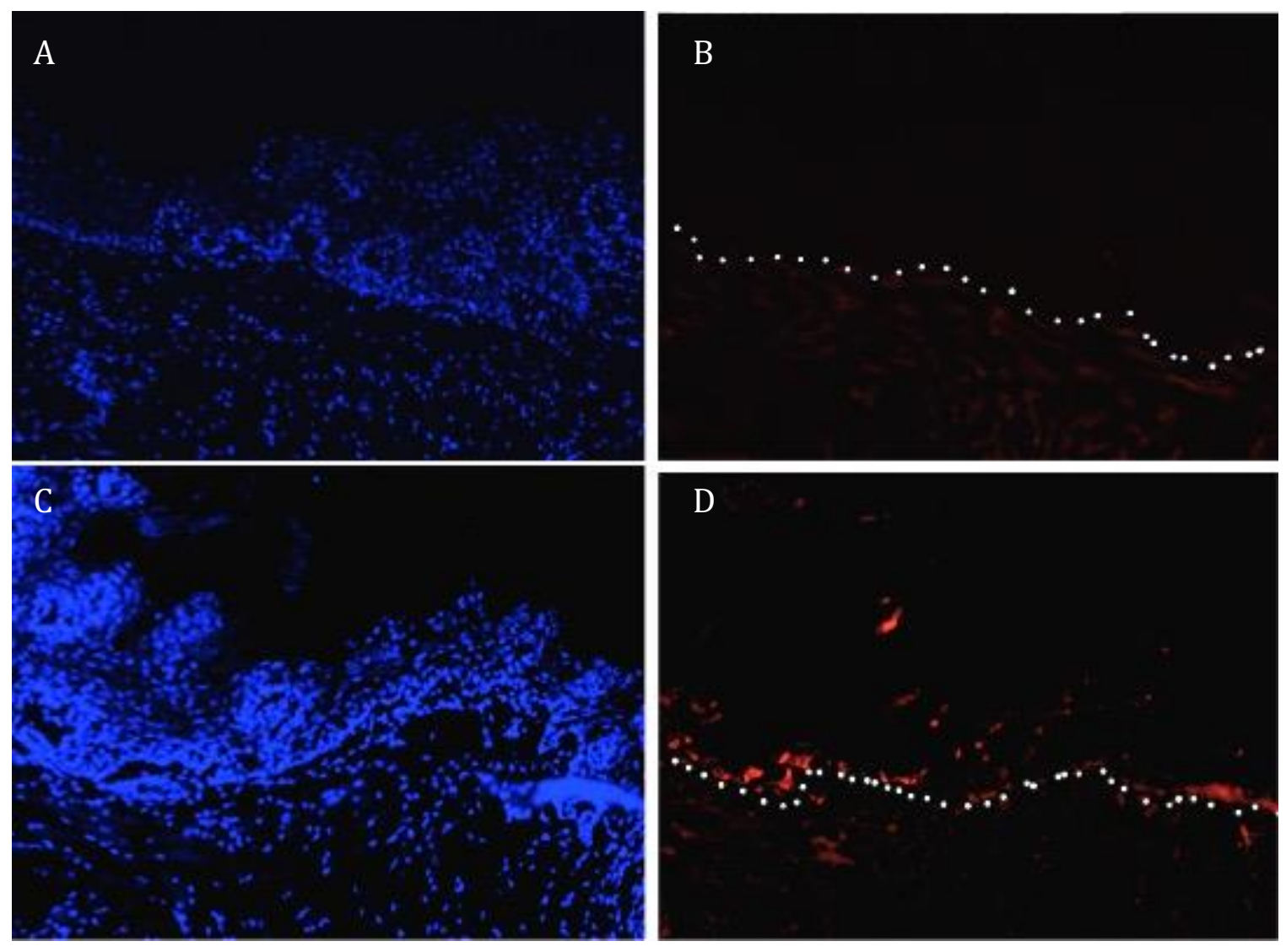

DAPI, Axin2

Figure 11. Fluorescent reporter (Axin2) in papillary hyperplasia and OSCC. A. DAPI in papillary epithelial hyperplasia B. Axin2 in papillary epithelial hyperplasia C. DAPI in OSCC D. Axin2 in OSCC.

Interestingly we observed that the fluorescent reporter (tdTomato) of Axin2 was noted in scattered basal and suprabasal tumor cells in OSCC tumors, suggesting that Wnt signaling was activated, specifically at the invasive front (Fig. 11. C-D). This pattern was not noted in papillary hyperplasia (Fig. 11. A-B).

Further, we wanted to determine the co-expression of these Axin2 positive cells with K5, 
a keratin marker of basal epithelial cells in OSCC and papillary epithelial hyperplasia.

The results of these studies were promising and consistent with the results of the previous experiments.

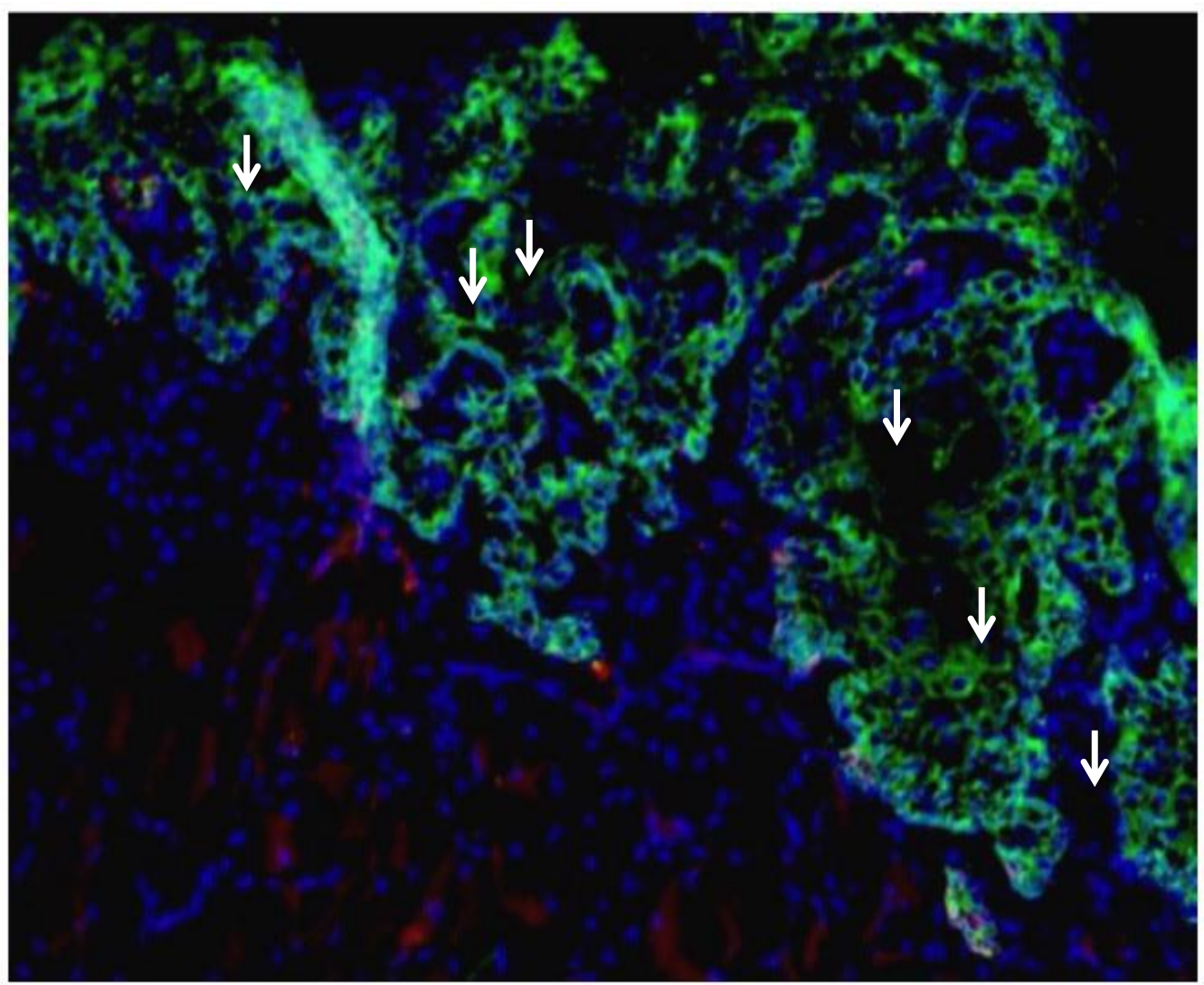

$D A P I$, Axin2, K5

Figure 12. Fluorescent reporter (Axin2) in OSCC. DAPI, Axin2 and K5 in OSCC. Axin2/K5 double positive cells (white arrows).

Scattered cells that were positive for K5 (green) were also positive for the Axin2 (tdTomato) reporter (less than 5\%) (Fig. 12), indicating that Wnt signaling was active in a small population of basal epithelial tumor cells. This was not noted in papillary hyperplasia (Fig. 13), and interestingly the K5 staining pattern was also distinctly different from what was observed in papillary hyperplasia. In OSCC, the K5 staining was 
strongly and uniformly present through the full thickness of the epithelium, indicating a loss of normal epithelial polarity.

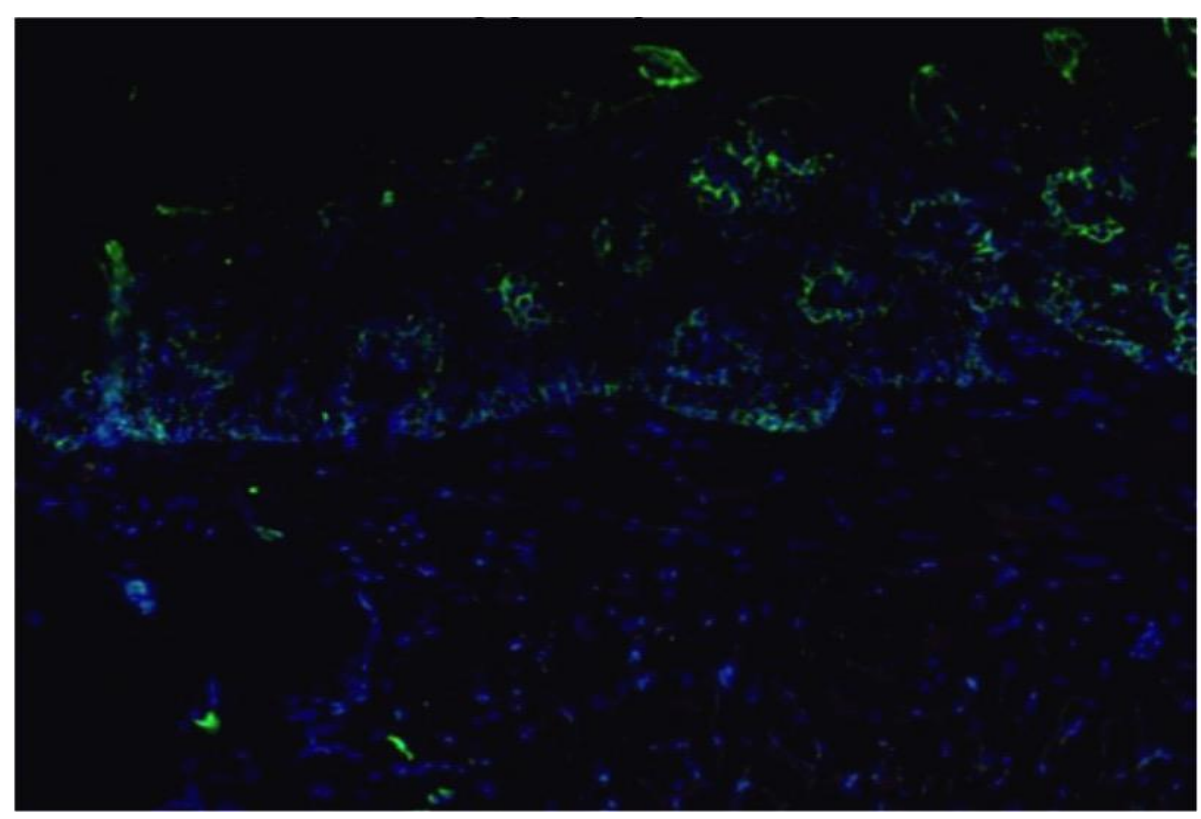

\section{DAPI, Axin2, K5}

Figure 13. Fluorescent reporter (Axin2) in papillary hyperplasia. DAPI, Axin2 and $\mathrm{K} 5$ in papillary epithelial hyperplasia.

\section{Axin2 induction in organoids of primary OSCC cells reveals evidence of Wnt}

\section{signaling}

To further pursue lineage-tracing studies, an in vitro 3-D platform was set up to culture organoids with primary OSCC tumor cells (Axin2-CreERT/YFP reporter). Tumor cells were isolated, cultured and passaged twice to obtain more robust and stable populations. 


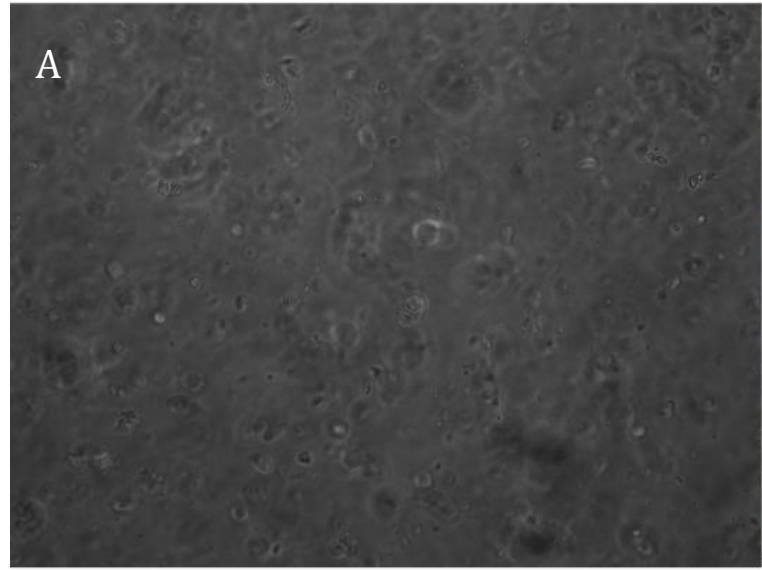

Bright field

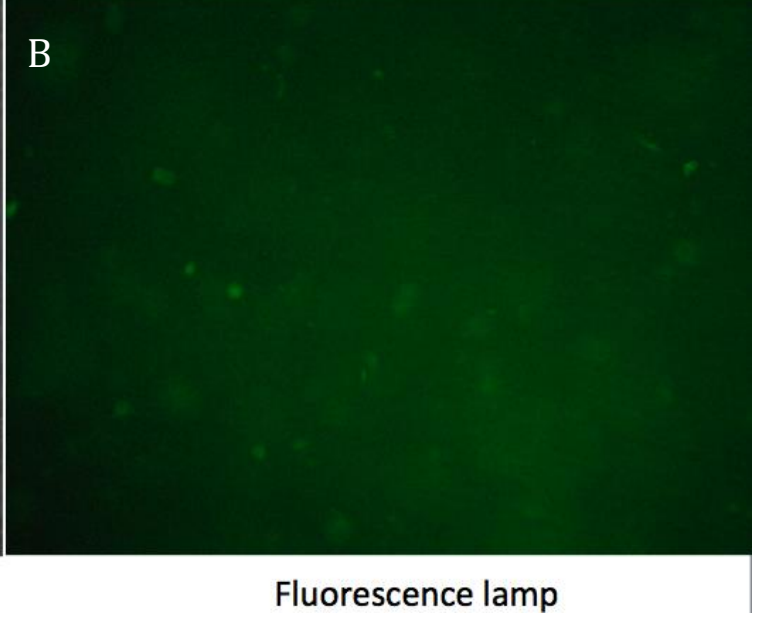

Figure 14. Axin2 induction in OSCC organoids A. Bright field B. Fluorescence lamp.

Under the bright field lamp, organoids appeared to be cohesive clusters of viable keratinocytes (Fig. 14A). After the addition of tamoxifen, the presence of Axin2 positive cells was noted in the 3-D organoids (Fig. 14B) suggesting the evidence of Wnt activity in the tumor cells.

\section{Wnt-responsive CICs are capable of forming organoids}

Two weeks after tamoxifen induction, cryosections of the 3-D organoids from primary OSCC tumors (with Axin2-CreERT/YFP reporter) were obtained. Immunofluorescence studies of these sections for native fluorescence were performed to study the expression patterns and overall structure of the organoids. YFP positive cells formed organoids based on the potential clonal expansion of Axin2+ OSCC cells (Fig. 15) demonstrating the stemness of these tumor cells. 
Figure 15. 3-D Organoid cryosection. Two weeks after in-vitro tamoxifen induction.

\section{DISCUSSION:}

Finally, we aimed to characterize CICs in OSCC based on the Wnt/ $\beta$-catenin signaling pathway. To achieve this, we performed both in vitro and in vivo lineage-tracing experiments. We utilized the inducible Cre reporter with tamoxifen in the 4-NQO mouse model to study the behavior of CICs and trace the resulting clones in their native environment and 3-D organoids. With the help of a fluorescent reporter (tdTomato or YFP) linked to the downstream genes of Wnt/ $\beta$-catenin pathway (Axin2), we were able to visualize these rare cells. In OSCC tumors, Axin2 positive cells were noted in the basal cells in the invasive front of OSCC. On the other hand, Axin2 positive cells were not noted in benign papillary epithelial hyperplasia. The results of these experiments provided further evidence of upregulation of Wnt signaling activity in a subpopulation of OSCC cells.

We attempted transplantation assays in immunodeficient mice (Rag $2^{-/}$, Nude and NODSCID) to demonstrate the stem-like features of CICs present in primary OSCC tumors. 
Unfortunately, none of the injected tumors successfully engrafted in immunodeficient mice. Also, mice that developed tumors did not survive past 4-6 weeks after cessation of 4-NQO treatment, making establishing an in vivo lineage-tracing system extremely challenging. We thus set up an in vitro 3-D organoid platform to maintain and expand the primary OSCC tumor cells. Lineage-tracing experiments were carried out in the 3-D organoids by adding tamoxifen to individual wells. Two weeks following the addition of tamoxifen, clonal expansion of Axin2 + OSCC cells forming YFP + organoids were noted, thus highlighting the stem-like features of CICs in OSCC cells. 


\section{CHAPTER 6: CONCLUSIONS AND FUTURE DIRECTIONS}


This project aimed at characterizing CICs in OSCC based on the Wnt/ $\beta$-catenin signaling pathway. We were successfully able to establish a chemically induced model of carcinogenesis in mice. With this model, we were capable of generating premalignant lesions and primary OSCC tumors that were representative of the well-known premalignant/malignant phenotypes in human OSCC. It was thus established that the 4NQO OSCC mouse model served as a reliable surrogate of tobacco-associated human premalignancy and OSCC. After the carcinogenesis model was set up, the tumor bank was established, and we sought to further characterize these based on Wnt/ $\beta$-catenin signaling activity. The evidence of this activity was generated by immunohistochemical and immunofluorescence studies with downstream markers of Wnt signaling. Finally, we identified CICs in OSCC, active for Wnt signaling using lineage-tracing strategies in vivo and 3-D organoids. We were able to link features of stemness of CICs to Wnt signaling activity and highlight the rare populations of CICs. In the future, understanding the timeline of when CIC-like features are acquired in premalignancy and full-blown malignant tumors will be crucial. For this we will need to explore more efficient methods of in vivo lineage-tracing. The major issue we dealt with in trying to lineage trace for extended periods of time was that most mice did not survive for over 4-6 weeks after developing tumors. Some of the less ideal, alternate systems that may be employed in the future to study CICs include human OSCC cell lines and xenograft models. Although we based our study on Wnt signaling pathway activity in OSCC CICs, we cannot rule out the possibility of the complex interplay between various signaling pathways known to be dysregulated in epithelial cancers, such as Hedgehog and Notch pathways. To address this in the future, we plan to generate a cohort of mice with reporter lines for other 
signaling pathways such as Gli1 and Bmil for Sonic hedgehog pathway. We are also keen on being able to successfully setup a transplantation model and will resort to utilizing more robust human OSCC cell lines and even patient samples in the future. Unfortunately, this platform is time-consuming and can be expensive to perform. We will also explore the possibility of isolating CIC-enriched organoids and their engraftment rates in immunodeficient mice.

To the end, the 3-D organoid system will be used extensively to test therapeutic drugs against OSCC CICs. Based on the results of our study, it will be interesting to study the response of OSCC cells to Wnt signaling antagonists. Organoid-forming assays may be applied to quantitatively determine how different subclones of cancer cells respond to therapeutic targets. Ultimately we can apply the results of such experiments in human OSCC cell lines and human samples. 


\section{REFERENCES:}

(1) Ferlay J, Soerjomataram I, Dikshit R, et al. Cancer incidence and mortality worldwide: sources, methods and major patterns in GLOBOCAN 2012. International journal of cancer 2015: 136: E359-386.

(2) Siegel RL, Miller KD, Jemal A. Cancer statistics, 2016. CA: a cancer journal for clinicians 2016: 66: 7-30.

(3) Jemal A, Bray F, Center MM, Ferlay J, Ward E, Forman D. Global cancer statistics. CA: a cancer journal for clinicians 2011: 61: 69-90.

(4) Warnakulasuriya S. Living with oral cancer: epidemiology with particular reference to prevalence and life-style changes that influence survival. Oral oncology 2010: 46: 407-410.

(5) de Camargo Cancela M, de Souza DL, Curado MP. International incidence of oropharyngeal cancer: a population-based study. Oral oncology 2012: 48: 484490.

(6) Herrero R, Castellsague X, Pawlita M, et al. Human papillomavirus and oral cancer: the International Agency for Research on Cancer multicenter study. Journal of the National Cancer Institute 2003: 95: 1772-1783.

(7) McBride KA, Ballinger ML, Killick E, et al. Li-Fraumeni syndrome: cancer risk assessment and clinical management. Nature reviews Clinical oncology 2014: 11: 260-271.

(8) Tanaka A, Weinel S, Nagy N, et al. Germline mutation in ATR in autosomaldominant oropharyngeal cancer syndrome. Am J Hum Genet 2012: 90: 511-517.

(9) Kutler DI, Auerbach AD, Satagopan J, et al. High incidence of head and neck squamous cell carcinoma in patients with Fanconi anemia. Archives of otolaryngology--head \& neck surgery 2003: 129: 106-112.

(10) Scully C, Langdon J, Evans J. Marathon of eponyms: 26 Zinsser-Engman-Cole syndrome (Dyskeratosis congenita). Oral diseases 2012: 18: 522-523.

(11) Warnakulasuriya S, Kovacevic T, Madden P, et al. Factors predicting malignant transformation in oral potentially malignant disorders among patients accrued over a 10-year period in South East England. Journal of oral pathology \& medicine : official publication of the International Association of Oral Pathologists and the American Academy of Oral Pathology 2011: 40: 677-683.

(12) Al-Hashimi I, Schifter M, Lockhart PB, et al. Oral lichen planus and oral lichenoid lesions: diagnostic and therapeutic considerations. Oral surgery, oral medicine, oral pathology, oral radiology, and endodontics 2007: 103 Suppl: S25 e21-12.

(13) Petti S. Pooled estimate of world leukoplakia prevalence: a systematic review. Oral oncology 2003: 39: 770-780.

(14) Silverman S, Jr., Gorsky M, Lozada F. Oral leukoplakia and malignant transformation. A follow-up study of 257 patients. Cancer 1984: 53: 563-568.

(15) Hsue SS, Wang WC, Chen CH, Lin CC, Chen YK, Lin LM. Malignant transformation in 1458 patients with potentially malignant oral mucosal disorders: a follow-up study based in a Taiwanese hospital. Journal of oral pathology \& medicine : official publication of the International Association of Oral Pathologists and the American Academy of Oral Pathology 2007: 36: 25-29. 
(16) Brouns E, Baart J, Karagozoglu K, Aartman I, Bloemena E, van der Waal I. Malignant transformation of oral leukoplakia in a well-defined cohort of 144 patients. Oral diseases 2014: 20: e19-24.

(17) Schepman KP, van der Meij EH, Smeele LE, van der Waal I. Malignant transformation of oral leukoplakia: a follow-up study of a hospital-based population of 166 patients with oral leukoplakia from The Netherlands. Oral oncology 1998: 34: 270-275.

(18) Lee JJ, Hung HC, Cheng SJ, et al. Carcinoma and dysplasia in oral leukoplakias in Taiwan: prevalence and risk factors. Oral Surg Oral Med Oral Pathol Oral Radiol Endod 2006: 101: 472-480.

(19) Woo SB, Grammer RL, Lerman MA. Keratosis of unknown significance and leukoplakia: a preliminary study. Oral Surg Oral Med Oral Pathol Oral Radiol 2014: 118: 713-724.

(20) Goy J, Hall SF, Feldman-Stewart D, Groome PA. Diagnostic delay and disease stage in head and neck cancer: a systematic review. The Laryngoscope 2009: 119: 889-898.

(21) Haddad RI, Shin DM. Recent advances in head and neck cancer. The New England journal of medicine 2008: 359: 1143-1154.

(22) Algazi AP, Grandis JR. Head and neck cancer in 2016: A watershed year for improvements in treatment? Nature reviews Clinical oncology 2017: 14: 76-78.

(23) Schmitz S, Ang KK, Vermorken J, et al. Targeted therapies for squamous cell carcinoma of the head and neck: current knowledge and future directions. Cancer treatment reviews 2014: 40: 390-404.

(24) Forastiere A, Koch W, Trotti A, Sidransky D. Head and neck cancer. The New England journal of medicine 2001: 345: 1890-1900.

(25) Slaughter DP, Southwick HW, Smejkal W. Field cancerization in oral stratified squamous epithelium; clinical implications of multicentric origin. Cancer 1953: 6: 963-968.

(26) Lechner M, Frampton GM, Fenton T, et al. Targeted next-generation sequencing of head and neck squamous cell carcinoma identifies novel genetic alterations in HPV+ and HPV- tumors. Genome Med 2013: 5: 49.

(27) Stransky N, Egloff AM, Tward AD, et al. The mutational landscape of head and neck squamous cell carcinoma. Science 2011: 333: 1157-1160.

(28) Agrawal N, Frederick MJ, Pickering CR, et al. Exome sequencing of head and neck squamous cell carcinoma reveals inactivating mutations in NOTCH1. Science 2011: 333: 1154-1157.

(29) Cancer Genome Atlas N. Comprehensive genomic characterization of head and neck squamous cell carcinomas. Nature 2015: 517: 576-582.

(30) Morris LG, Ramaswami D, Chan TA. The FAT epidemic: a gene family frequently mutated across multiple human cancer types. Cell Cycle 2013: 12: 1011-1012.

(31) Marie H, Pratt SJ, Betson M, et al. The LIM protein Ajuba is recruited to cadherin-dependent cell junctions through an association with alpha-catenin. J Biol Chem 2003: 278: 1220-1228.

(32) Lawrence MS, Stojanov P, Mermel CH, et al. Discovery and saturation analysis of cancer genes across 21 tumour types. Nature 2014: 505: 495-501. 
(33) Chau NG, Li YY, Jo VY, et al. Incorporation of Next-Generation Sequencing into Routine Clinical Care to Direct Treatment of Head and Neck Squamous Cell Carcinoma. Clinical cancer research : an official journal of the American Association for Cancer Research 2016: 22: 2939-2949.

(34) Egger G, Liang G, Aparicio A, Jones PA. Epigenetics in human disease and prospects for epigenetic therapy. Nature 2004: 429: 457-463.

(35) Asokan GS, Jeelani S, Gnanasundaram N. Promoter hypermethylation profile of tumour suppressor genes in oral leukoplakia and oral squamous cell carcinoma. J Clin Diagn Res 2014: 8: ZC09-12.

(36) Yeh KT, Shih MC, Lin TH, et al. The correlation between CpG methylation on promoter and protein expression of E-cadherin in oral squamous cell carcinoma. Anticancer Res 2002: 22: 3971-3975.

(37) Kulkarni V, Saranath D. Concurrent hypermethylation of multiple regulatory genes in chewing tobacco associated oral squamous cell carcinomas and adjacent normal tissues. Oral oncology 2004: 40: 145-153.

(38) Kato K, Hara A, Kuno T, et al. Aberrant promoter hypermethylation of p16 and MGMT genes in oral squamous cell carcinomas and the surrounding normal mucosa. J Cancer Res Clin Oncol 2006: 132: 735-743.

(39) Lagos-Quintana M, Rauhut R, Lendeckel W, Tuschl T. Identification of novel genes coding for small expressed RNAs. Science 2001: 294: 853-858.

(40) Bartel DP. MicroRNAs: genomics, biogenesis, mechanism, and function. Cell 2004: 116: 281-297.

(41) Gorenchtein M, Poh CF, Saini R, Garnis C. MicroRNAs in an oral cancer context - from basic biology to clinical utility. J Dent Res 2012: 91: 440-446.

(42) Koshizuka K, Hanazawa T, Fukumoto I, Kikkawa N, Okamoto Y, Seki N. The microRNA signatures: aberrantly expressed microRNAs in head and neck squamous cell carcinoma. J Hum Genet 2017: 62: 3-13.

(43) Shackleton M, Quintana E, Fearon ER, Morrison SJ. Heterogeneity in cancer: cancer stem cells versus clonal evolution. Cell 2009: 138: 822-829.

(44) Klein AM, Simons BD. Universal patterns of stem cell fate in cycling adult tissues. Development 2011: 138: 3103-3111.

(45) Driessens G, Beck B, Caauwe A, Simons BD, Blanpain C. Defining the mode of tumour growth by clonal analysis. Nature 2012: 488: 527-530.

(46) Schepers AG, Snippert HJ, Stange DE, et al. Lineage tracing reveals Lgr5+ stem cell activity in mouse intestinal adenomas. Science 2012: 337: 730-735.

(47) Vermeulen L, de Sousa e Melo F, Richel DJ, Medema JP. The developing cancer stem-cell model: clinical challenges and opportunities. Lancet Oncol 2012: 13: e83-89.

(48) Reya T, Morrison SJ, Clarke MF, Weissman IL. Stem cells, cancer, and cancer stem cells. Nature 2001: 414: 105-111.

(49) Leblond CP, Walker BE. Renewal of cell populations. Physiol Rev 1956: 36: 255276.

(50) Akashi K, Weissman IL. Developmental Biology of Hematopoiesis. In: Zon LI, ed. New York: Oxford Univ. Press, 2001: 15-34.

(51) Moon RT, Bowerman B, Boutros M, Perrimon N. The promise and perils of Wnt signaling through beta-catenin. Science 2002: 296: 1644-1646. 
(52) Bhanot P, Brink M, Samos CH, et al. A new member of the frizzled family from Drosophila functions as a Wingless receptor. Nature 1996: 382: 225-230.

(53) Wehrli M, Dougan ST, Caldwell K, et al. arrow encodes an LDL-receptor-related protein essential for Wingless signalling. Nature 2000: 407: 527-530.

(54) Nusse R, Fuerer C, Ching W, et al. Wnt signaling and stem cell control. Cold Spring Harbor symposia on quantitative biology 2008: 73: 59-66.

(55) Clevers H, Loh KM, Nusse R. Stem cell signaling. An integral program for tissue renewal and regeneration: Wnt signaling and stem cell control. Science 2014: 346: 1248012.

(56) Lim X, Tan SH, Koh WL, et al. Interfollicular epidermal stem cells self-renew via autocrine Wnt signaling. Science 2013: 342: 1226-1230.

(57) Pardal R, Clarke MF, Morrison SJ. Applying the principles of stem-cell biology to cancer. Nature reviews Cancer 2003: 3: 895-902.

(58) Zhu AJ, Watt FM. beta-catenin signalling modulates proliferative potential of human epidermal keratinocytes independently of intercellular adhesion. Development 1999: 126: 2285-2298.

(59) Malanchi I, Peinado H, Kassen D, et al. Cutaneous cancer stem cell maintenance is dependent on beta-catenin signalling. Nature 2008: 452: 650-653.

(60) Oskarsson T, Batlle E, Massague J. Metastatic stem cells: sources, niches, and vital pathways. Cell stem cell 2014: 14: 306-321.

(61) Singh A, Settleman J. EMT, cancer stem cells and drug resistance: an emerging axis of evil in the war on cancer. Oncogene 2010: 29: 4741-4751.

(62) Yu Z, Weinberger PM, Provost E, et al. beta-Catenin functions mainly as an adhesion molecule in patients with squamous cell cancer of the head and neck. Clinical cancer research : an official journal of the American Association for Cancer Research 2005: 11: 2471-2477.

(63) Pukkila MJ, Virtaniemi JA, Kumpulainen EJ, et al. Nuclear beta catenin expression is related to unfavourable outcome in oropharyngeal and hypopharyngeal squamous cell carcinoma. J Clin Pathol 2001: 54: 42-47.

(64) Tanaka N, Odajima T, Ogi K, Ikeda T, Satoh M. Expression of E-cadherin, alphacatenin, and beta-catenin in the process of lymph node metastasis in oral squamous cell carcinoma. British journal of cancer 2003: 89: 557-563.

(65) Liu LK, Jiang XY, Zhou XX, Wang DM, Song XL, Jiang HB. Upregulation of vimentin and aberrant expression of E-cadherin/beta-catenin complex in oral squamous cell carcinomas: correlation with the clinicopathological features and patient outcome. Mod Pathol 2010: 23: 213-224.

(66) Osei-Sarfo K, Tang XH, Urvalek AM, Scognamiglio T, Gudas LJ. The molecular features of tongue epithelium treated with the carcinogen 4-nitroquinoline-1-oxide and alcohol as a model for HNSCC. Carcinogenesis 2013: 34: 2673-2681.

(67) Song J, Chang I, Chen Z, Kang M, Wang CY. Characterization of side populations in HNSCC: highly invasive, chemoresistant and abnormal Wnt signaling. PloS one 2010: 5: e11456.

(68) Pannone G, Bufo P, Santoro A, et al. WNT pathway in oral cancer: epigenetic inactivation of WNT-inhibitors. Oncology reports 2010: 24: 1035-1041.

(69) Kudo Y, Kitajima S, Ogawa I, et al. Invasion and metastasis of oral cancer cells require methylation of E-cadherin and/or degradation of membranous beta- 
catenin. Clinical cancer research : an official journal of the American Association for Cancer Research 2004: 10: 5455-5463.

(70) Gasparoni A, Chaves A, Fonzi L, Johnson GK, Schneider GB, Squier CA. Subcellular localization of beta-catenin in malignant cell lines and squamous cell carcinomas of the oral cavity. Journal of oral pathology \& medicine : official publication of the International Association of Oral Pathologists and the American Academy of Oral Pathology 2002: 31: 385-394.

(71) Iwai S, Yonekawa A, Harada C, et al. Involvement of the Wnt-beta-catenin pathway in invasion and migration of oral squamous carcinoma cells. Int J Oncol 2010: 37: 1095-1103.

(72) Fracalossi AC, Silva Mde S, Oshima CT, Ribeiro DA. Wnt/beta-catenin signalling pathway following rat tongue carcinogenesis induced by 4nitroquinoline 1-oxide. Experimental and molecular pathology 2010: 88: 176-183.

(73) Gonzalez-Moles MA, Scully C, Ruiz-Avila I, Plaza-Campillo JJ. The cancer stem cell hypothesis applied to oral carcinoma. Oral oncology 2013: 49: 738-746.

(74) Prince ME, Sivanandan R, Kaczorowski A, et al. Identification of a subpopulation of cells with cancer stem cell properties in head and neck squamous cell carcinoma. Proceedings of the National Academy of Sciences of the United States of America 2007: 104: 973-978.

(75) Beck B, Blanpain C. Unravelling cancer stem cell potential. Nature reviews Cancer 2013: 13: 727-738.

(76) Chen D, Wu M, Li Y, et al. Targeting BMI1+ Cancer Stem Cells Overcomes Chemoresistance and Inhibits Metastases in Squamous Cell Carcinoma. Cell stem cell 2017.

(77) Chen J, Li Y, Yu TS, et al. A restricted cell population propagates glioblastoma growth after chemotherapy. Nature 2012: 488: 522-526.

(78) Czerninski R, Amornphimoltham P, Patel V, Molinolo AA, Gutkind JS. Targeting mammalian target of rapamycin by rapamycin prevents tumor progression in an oral-specific chemical carcinogenesis model. Cancer Prev Res (Phila) 2009: 2: 27-36.

(79) van Amerongen R, Bowman AN, Nusse R. Developmental stage and time dictate the fate of Wnt/beta-catenin-responsive stem cells in the mammary gland. Cell stem cell 2012: 11:387-400.

(80) Neville BW, et al Oral and maxillofacial pathology: Elsevier Health Sciences, 2015.

(81) Kretzschmar K, Watt FM. Lineage tracing. Cell 2012: 148: 33-45.

(82) Metzger D, Clifford J, Chiba H, Chambon P. Conditional site-specific recombination in mammalian cells using a ligand-dependent chimeric Cre recombinase. Proceedings of the National Academy of Sciences of the United States of America 1995: 92: 6991-6995.

(83) Mao X, Fujiwara Y, Chapdelaine A, Yang H, Orkin SH. Activation of EGFP expression by Cre-mediated excision in a new ROSA26 reporter mouse strain. Blood 2001: 97: 324-326. 